\title{
CFD Analysis of Nozzle Jet Plume Effects on Sonic Boom Signature
}

\author{
Trong T. Bui ${ }^{*}$ \\ NASA Dryden Flight Research Center \\ Edwards, California
}

\begin{abstract}
An axisymmetric full Navier-Stokes computational fluid dynamics study is conducted to examine nozzle exhaust jet plume effects on the sonic boom signature of a supersonic aircraft. A simplified axisymmetric nozzle geometry, representative of the nozzle on the NASA Dryden NF-15B Lift and Nozzle Change Effects on Tail Shock research airplane, is considered. The computational fluid dynamics code is validated using available wind-tunnel sonic boom experimental data. The effects of grid size, spatial order of accuracy, grid type, and flow viscosity on the accuracy of the predicted sonic boom pressure signature are quantified. Grid lines parallel to the Mach wave direction are found to give the best results. Second-order accurate upwind methods are required as a minimum for accurate sonic boom simulations. The highly underexpanded nozzle flow is found to provide significantly more reduction in the tail shock strength in the sonic boom $\mathrm{N}$-wave pressure signature than perfectly expanded and overexpanded nozzle flows. A tail shock train in the sonic boom signature is observed for the highly underexpanded nozzle flow. Axisymmetric computational fluid dynamics simulations show the flow physics inside the F-15 nozzle to be nonisentropic and complex. Although the one-dimensional isentropic nozzle plume results look reasonable, they fail to capture the sonic boom shock train in the highly underexpanded nozzle flow.
\end{abstract}

\section{Nomenclature}

$\mathrm{BC}$

$=$ boundary condition

CFD

$=$ computational fluid dynamics

CFL = Courant-Friedrichs-Lewy

$C_{p}$

$=$ pressure coefficient, $\left(p-p_{\infty}\right) / q_{\infty}$

$\mathrm{D}$

deg

$h$

$\mathrm{L}$

$=$ nozzle exit diameter or maximum diameter of the body of revolution

$=$ degree

$=$ radial distance from the axisymmetric centerline of the test article in the $y$ direction

$=$ length of the test article

LDFSS $\quad=$ Edwards' low dissipation flux split scheme

MUSCL = Monotone Upstream-centered Schemes for Conservation Laws

NPR $=$ nozzle pressure ratio, the ratio of nozzle total pressure to freestream static pressure

$p \quad=$ static pressure

$p_{\text {tot }} \quad=$ total pressure

$p_{\infty} \quad=$ freestream static pressure

$q_{\infty} \quad=$ freestream dynamic pressure

$\mathrm{TN}=$ technical note

TVD $=$ total variation diminishing

VULCAN $=$ Viscous Upwind ALgorithm for Complex Flow ANalysis

$x \quad=$ stream-wise distance from the nose tip of the bullet body

$y \quad=$ radial distance normal to the axisymmetric centerline of the model

\footnotetext{
* Aerospace Engineer, Research Aerodynamics, Propulsion, and Performance Branch, P.O. Box 273/MS 4840B,
} AIAA Senior Member. 


$\begin{array}{ll}y^{+} & =\text {wall normal distance in boundary layer wall units } \\ 1 \mathrm{D} & =\text { one-dimensional } \\ \Delta p & =\text { local static pressure minus freestream static pressure } \\ \Delta x & =\text { distance to the point where the sonic boom pressure signature curve crosses zero } \\ \kappa & =\text { MUSCL interpolation coefficient }\end{array}$

\section{Introduction}

At supersonic speeds, the pressure distribution around an airplane results in the classic sonic boom $\mathrm{N}$-wave pressure signature in the far field that consists of, from front to back, a bow shock, expansion fan, and terminal tail shock. To minimize the impact of the sonic boom on the ground, the far field pressure signature from a supersonic airplane must be modified and flattened out as much as possible. ${ }^{1}$ Recent flight research experiments conducted at the NASA Dryden Flight Research Center (Edwards, California) focused on the front part of the sonic boom. The Shaped Sonic Boom Demonstration (SSBD) project ${ }^{2}$ demonstrated in flight that the bow shock could be shaped and significantly attenuated by careful shaping of the fore body of a modified F-5E aircraft (Northrop Corporation, now Northrop Grumman Corporation). The Gulfstream Quiet Spike ${ }^{\mathrm{TM}}$ project $^{3}$ (Gulfstream Aerospace Corporation, A General Dynamics Company, Savannah, Georgia) evaluated the structural dynamic characteristics of a shaped telescoping boom that extended out of the forward fuselage of a NASA F-15B aircraft (McDonnell Douglas Corporation, now The Boeing Company) and provided near-field pressure measurements of the boom in flight.

Following these highly successful flight research projects, the Lift and Nozzle Change Effects on Tail Shock (LaNCETS) flight research project was initiated to investigate the effects of changing the lift distribution and jet engine nozzle area ratio on the tail shock of a supersonic airplane. The primary goals of this project were to validate the computational fluid dynamics (CFD) models and explore ways to reduce the tail shock in the aft portion of the classical N-wave pressure signature of a supersonic airplane. Two F-15 aircraft were used in the LaNCETS flight research effort. The sonic boom shock signature of the F-15 research aircraft (NASA NF-15B, tail No. 837), shown in Fig. 1, is obtained by the F-15 probing aircraft (NASA F-15B, tail No. 836). The NF-15B was selected as the research aircraft because of its unique canard and engine nozzle systems. The canard could be deflected to alter the longitudinal lift distribution of the aircraft, and the aircraft nozzle area ratio could be changed. Thus the effects on the sonic boom resulting from lift distribution and nozzle changes could be evaluated in flight. The aircraft is also capable of thrust vectoring, and thrust vectoring could potentially alter both the lift distribution and nozzle plume flows of the aircraft. The project schedule and budget, however, did not permit thrust-vectoring studies in this effort. This computational study directly supports the LaNCETS flight research project by providing detailed CFD analysis of the flow physics involved with the interactions between the jet plume from an axisymmetric nozzle and the tail shock of the sonic boom.

Since the 1960s, the engine jet plume of a supersonic airplane has been recognized as an important factor in shaping the terminal tail shock in the sonic boom pressure signature. Analytical as well as experimental efforts have been undertaken to predict the shape of the jet plume and its effects on the airplane's sonic boom. In reference 4, simple expressions for estimating the initial contour of a jet plume were developed from the linearized potential flow equation. The pressure field of a supersonic stream surrounding the jet was also determined. A combined analytical and experimental investigation was conducted in reference 5, in which measurements were made for jet flows at Mach 2.2 in the 4- by 4-ft supersonic pressure wind tunnel at the NASA Langley Research Center (Hampton, Virginia). With the far field measurements from the wind-tunnel tests, an inverse application of the method of characteristics was used to analytically calculate the jet plume shapes. The wind-tunnel data obtained in this particular research would have made a good CFD validation test case; however, the wind-tunnel measurements were taken relatively close to the model, at only one nozzle diameter away. Also, data were not available at multiple distances away from the model to validate a CFD code's ability to accurately propagate the sonic boom. Several jet plume shape prediction methods were compared in reference 6 . The Euler shock-fitting marching code was found to give relatively good agreement with semiempirically determined plume shapes. The comparison contained discrepancies, however, which were attributed to nonisentropic internal nozzle flow. If only the plume shape in the vicinity of the nozzle exit is required, then the simplified plume boundary prediction method outlined in reference 7 could be used for an underexpanded axisymmetric jet exhausting into a supersonic external flow. Turbulent CFD analysis was conducted for jet plumes of isolated nozzle configurations in reference 8. In this work, near-field pressure signatures were computed at one nozzle diameter (D) from the nozzle centerline and compared to the windtunnel data published in reference 5. Near-field CFD solutions at less than $10 \mathrm{D}$ from the nozzle centerline were extrapolated to the far-field sonic boom signatures using a sonic boom propagation analysis code. Results showed 
that there is a reduction in the sonic boom N-wave signature as the nozzle pressure ratio (NPR) is increased from 6 to 10 .

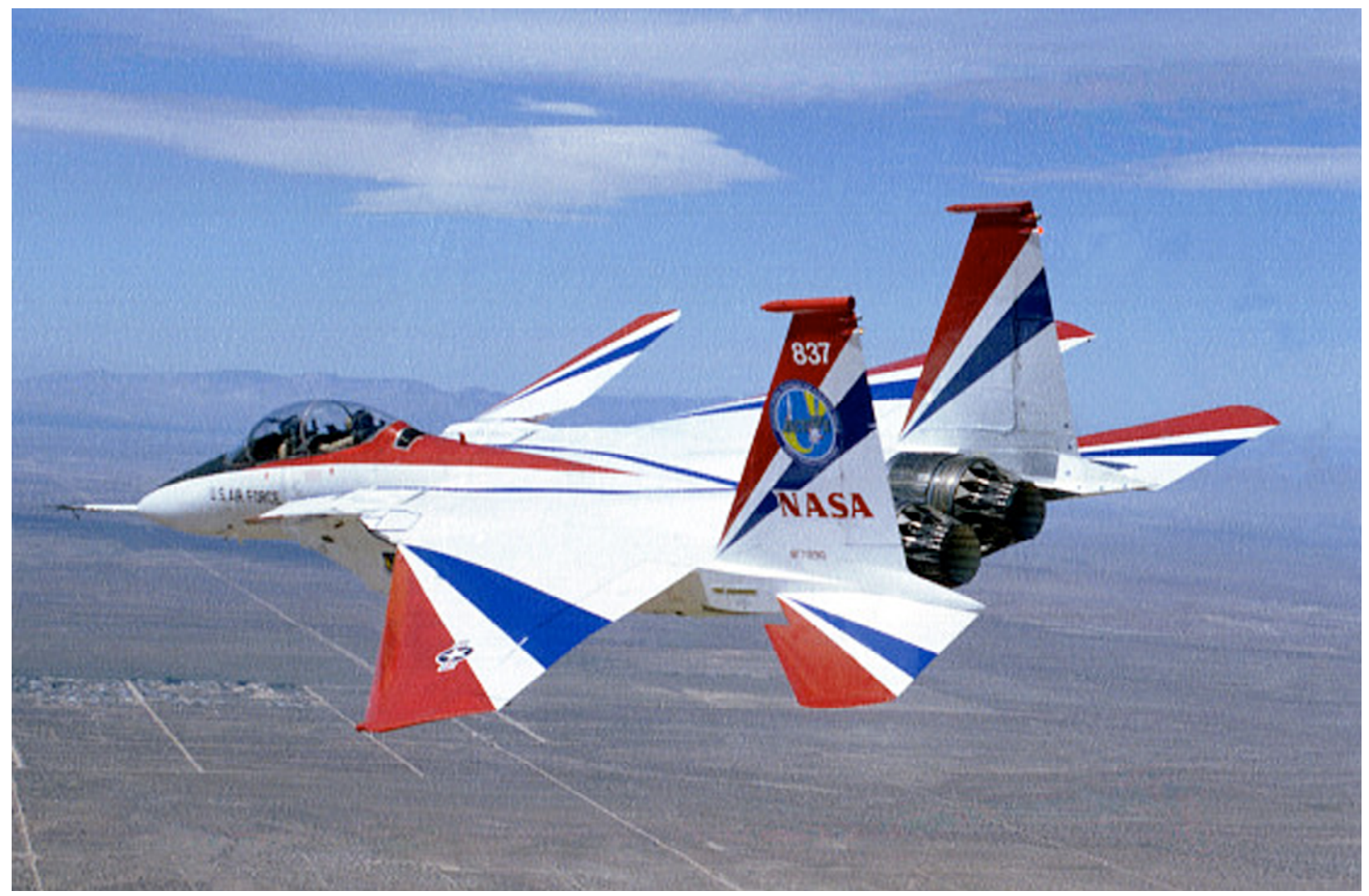

Figure 1. The NASA NF-15B, tail No. 837, Lift and Nozzle Change Effects on Tail Shock (LaNCETS) research aircraft.

A structured finite-volume compressible full Navier-Stokes CFD code is used in the current study. This approach is not limited by the simplifying assumptions inherent in previous research using the linearized potential flow equation and method of characteristics. Also, this study is the first known jet plume sonic boom CFD study in which the full viscous flow field is modeled, without coupling to a sonic boom propagation analysis code, from the stagnation chamber of the nozzle to the far field external flow, taking into account all nonisentropic effects in the shocks, boundary layers, and free shear layers, and their interactions at distances up to $30 \mathrm{D}$ from the jet centerline. The effects of grid size, spatial order of accuracy, grid type, and flow viscosity on the accuracy of the predicted sonic boom signature are quantified. The detailed flow field within the jet plume and its interaction with the external supersonic flow are examined. By varying the ambient static pressures in the current CFD simulations, effects of imperfectly expanded jet plume on the resulting sonic boom are studied. The CFD solutions from both the axisymmetric nozzle and various one-dimensional (1D) axisymmetric nozzle approximations are compared. Finally, the nozzle boat tail and plenum area effects on the sonic boom signature are examined.

\section{Computational Fluid Dynamics Code Validation Study}

Sonic boom simulation is one of the more challenging applications of CFD, comparable in the level of difficulty to aeroacoustic CFD simulations. While typical CFD simulations of flows over wings and aircraft bodies only need to resolve the local flow around the bodies, sonic boom and aeroacoustic CFD simulations must resolve the flows accurately both in the vicinity of the bodies and in the far field regions. As a result, extremely large computational grids are required. Also, the numerical algorithms must be very accurate to propagate the sonic booms and acoustic waves faithfully without excessive dissipation and/or dispersion errors. As such, accuracy throughout the computational domain, not just at the body itself, is required. Before the CFD analysis for the axisymmetric nozzle 
was conducted, a CFD code validation study was performed to evaluate the various effects that grid topology, boundary conditions (BCs), and CFD code settings have on the quality of the sonic boom simulations.

\section{A. Analysis Description}

The Viscous Upwind ALgorithm for Complex Flow ANalysis (VULCAN) full Navier-Stokes CFD code ${ }^{9}$ is used in this report. The VULCAN code is a turbulent, nonequilibrium, finite-rate chemical kinetics, Navier-Stokes flow solver for structured, cell-centered, multiblock grids, and it is currently maintained and distributed (restricted to the U.S.) by the Hypersonic Air Breathing Propulsion Branch of the NASA Langley Research Center. For the nozzle flows under consideration, chemical kinetics is not expected to significantly alter the nozzle flow physics; therefore, the calorically perfect gas model is used. The axisymmetric flow approximation is used in the present analysis.

\section{Experimental Geometry}

A well-documented series of sonic boom wind-tunnel test cases are found in reference 10. In this reference, measurements of sonic boom pressure signatures were obtained for eight slender bodies of revolution at various normal distances up to 20 body lengths from the model centerline in the NASA Langley 4- by 4-ft supersonic pressure wind tunnel. The geometries and experimental measurements are provided in great detail, making it an excellent CFD code validation experiment for sonic boom propagation.

One particular test case selected from reference 10 was model 2, Mach 1.41. Model 2 was a cone cylinder body of revolution with a cone half-angle of $6.46 \mathrm{deg}$. In reference 11, the same model geometry was tested at higher Mach numbers, known as model 7. Only the Mach 1.41 test case in reference 10 was used in the present code validation study, because this test case was close to the primary Mach number used in the LaNCETS flights.

\section{Grid Topology}

Figure 2 shows the grid topologies used in this CFD code validation study. Axisymmetric structured CFD grids were used in the calculations. Only one grid block was necessary to model the flow domain extending in the radial direction from the cone cylinder body surface to the upper far field boundary. To assess the sensitivity of the CFD solution to grid topologies, two different grid types were used: grid lines parallel with the Mach wave direction, called the Mach aligned grid (Fig. 2a); and grid lines parallel with the axial, $x$, and radial, $y$, axisymmetric coordinate axes, called the orthogonal grid (Fig. 2b).

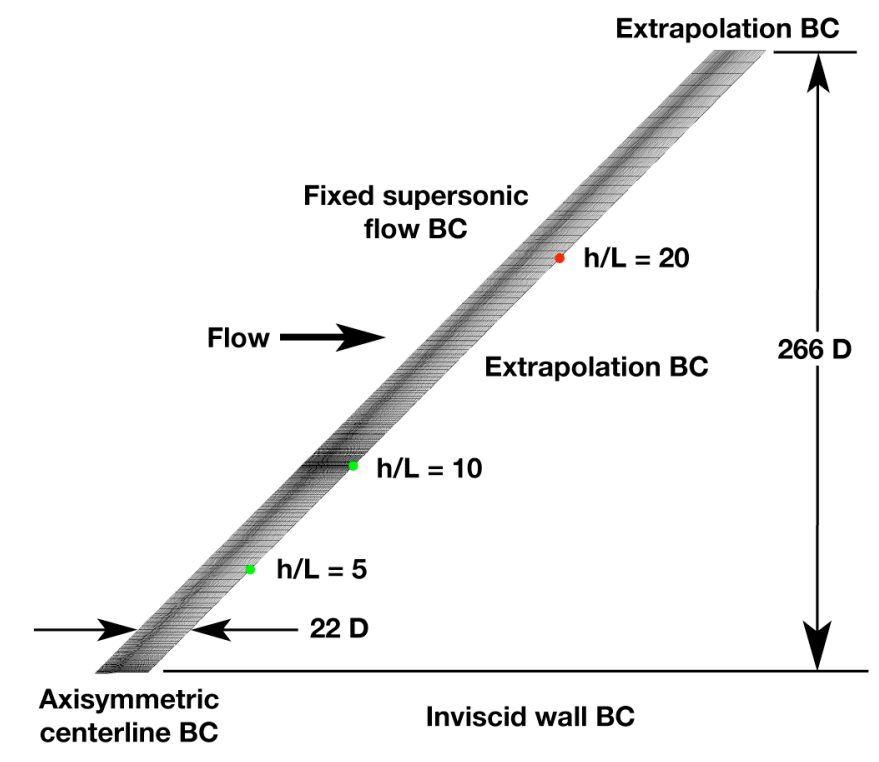

a) Mach aligned grid.

Figure 2. Computational fluid dynamics grid topologies for cone cylinder sonic boom validation test case. 


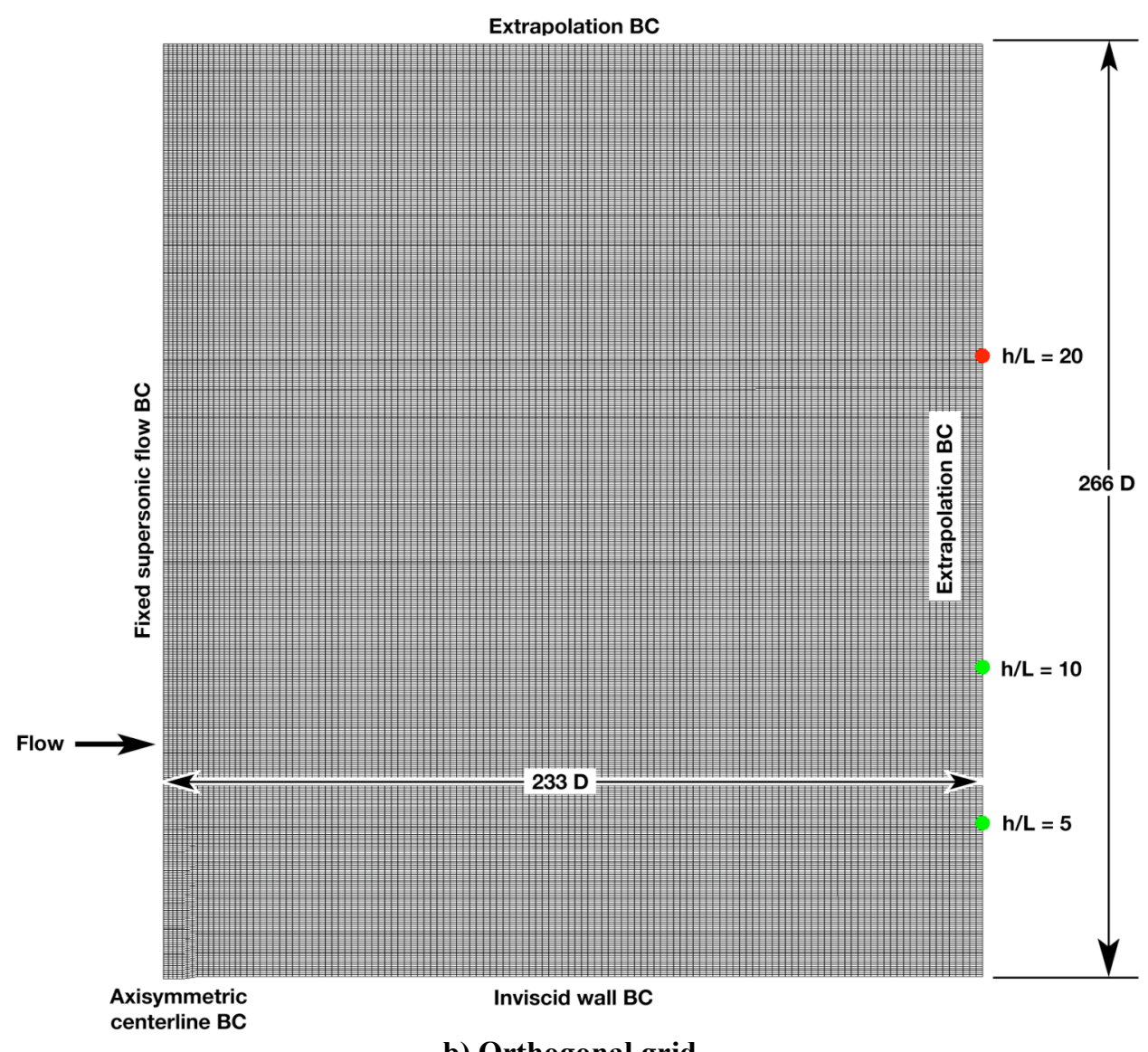

b) Orthogonal grid.

Figure 2. Concluded.

\section{Boundary Conditions and Initial Conditions}

Fixed supersonic inflow BC was used at the inflow (left) boundary. To match the wind-tunnel experiment conditions published in reference 10, the following inflow conditions were specified in the CFD simulations: a Mach number of 1.41 , total pressure of $68.95 \mathrm{kPa}$, and total temperature of $310.9 \mathrm{~K}$. Zeroth-order extrapolation was used for the downstream (right) and far field (top) boundaries. An axisymmetric centerline $\mathrm{BC}$ was used to model the axis of symmetry on the bottom grid boundary upstream of the cone cylinder tip, and inviscid wall BC was used to model the cone cylinder on the bottom grid boundary of the computational domain. Uniform freestream flow conditions were used as initial conditions throughout the computational domain.

\section{Computational Fluid Dynamics Solver Settings}

Axisymmetric CFD simulations were conducted using the VULCAN finite-volume, structured CFD code. The calorically perfect gas model was used with a ratio of specific heats value of 1.4 and a specific gas constant value of $287 \mathrm{~J} /(\mathrm{kg} \mathrm{K})$. In addition to the inviscid Euler approximation, viscous full Navier-Stokes computations with laminar as well as a two-equation turbulence model were conducted to evaluate the sensitivity of the solution to flow viscosity. The inviscid flux terms were discretized using the Edwards' low dissipation flux split scheme (LDFSS). ${ }^{12}$ Both the first-order method and the second-order $(\kappa=1 / 3)$ Monotone Upstream-centered Schemes for Conservation Laws (MUSCL) flux interpolation method were used. The van Leer total variation diminishing (TVD) flux limiter was used for the second-order method. To accelerate the iterative convergence, grid sequencing was used on three coarse grid levels. The simulations were considered iteratively converged when the L2 norm of the residuals became constant as a function of iterations. Figure 3 shows a sample residual history from a first-order simulation using grid sequencing with three coarse grids. Five thousand iterations were performed on each of the three coarse grid levels. More than 10,000 additional iterations were needed to drive the finest grid solution to convergence. Local time stepping was used to accelerate convergence. For the first-order upwind simulations, the Courant-Friedrichs-Lewy (CFL) number was ramped up from 0.1 to 3.0 in 5000 iterations for all grid levels. For the second-order upwind 
simulations, the CFL number was ramped up from 0.1 to 1.0 in 3000 iterations for each of the coarse grid sequences, and 0.1 to 0.3 in 3000 iterations for the final grid. The CFL numbers were smaller for the second-order simulations to avoid spurious pressure oscillations in the far field.

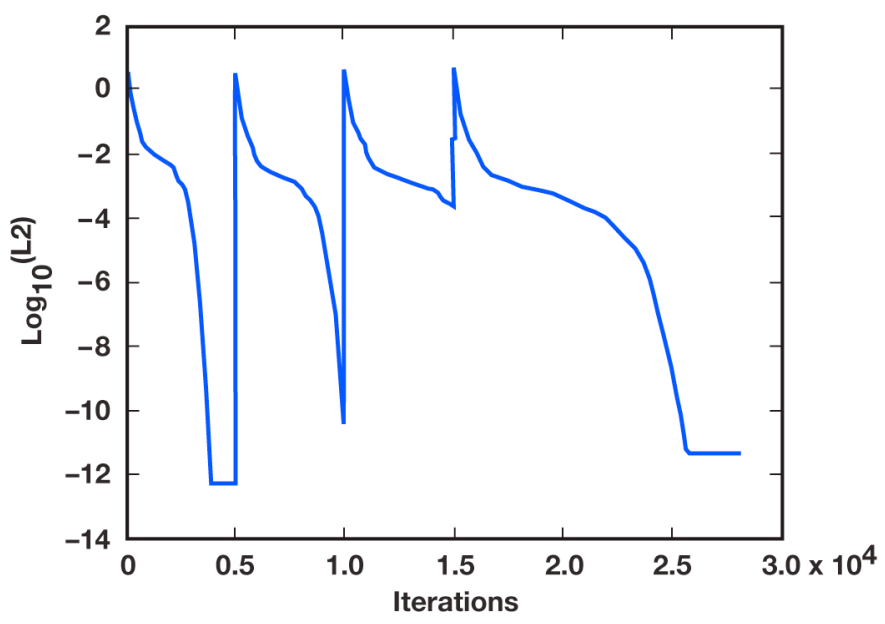

Figure 3. Typical residual history for cone cylinder sonic boom validation test case.

\section{B. Study of Grid Independence and Spatial Order of Accuracy}

Once all of the solutions were iteratively converged, a grid independence study was conducted to determine the grid size required for grid independent results. For the first-order LDFSS method, four different grid sizes were used for the Mach aligned grid: $2 X(513 \times 1761)$, double; $1 X(257 \times 881)$, normal; $\frac{1}{2} X(129 \times 441)$, half; and $\frac{1}{4} X$ $(65 \times 221)$, quarter. The quarter grid was not used in the second-order LDFSS method. Note that in the present terminology, the double grid actually has four times the total number of grid cells compared with the normal grid, because the number of grid cells is actually doubled both in the axial and radial directions.

Figure 4 presents the results of the studies on grid independence and spatial order of accuracy. The CFD sonic boom pressure signatures are compared to experimental data at three different radial distances away from the centerline of the model, $h / \mathrm{L}$, at 5,10 , and 20 . The pressures and distances in Fig. 4 are presented in the same nondimensional forms as the data from reference 10. It can be seen that the sonic boom pressure signature starts out with a rounded peak in the pressure distribution near the model $(h / \mathrm{L}=5)$, then becomes steeper and approaches the classic $\mathrm{N}$-wave shape in the far field $(h / \mathrm{L}=20)$.

It is important that a grid independence study be carefully conducted before any CFD results are used, because the numerical solutions depend on the grid size if grid independence is not yet reached. Figure 4 provides an example of this issue. If a grid independence study had not been conducted, then it would be wrongly concluded that the Euler approach models the current flow well, because the CFD first-order 1X grid results (red lines) have excellent agreement with the experimental data. The CFD results from the first-order $2 \mathrm{X}$ grid and all of the secondorder grids, however, actually depart from the first-order $1 \mathrm{X}$ grid and the experimental data. The grid independent CFD solution shows that the Euler approximation actually produced sharper and more exaggerated peaks and dips in the $\mathrm{N}$-wave signatures compared with the more rounded first-order $1 \mathrm{X}$ grid solution and the experimental data. A similar trend was reported with the analytical sonic boom prediction methods used in references 10 and 13 .

With the first-order method, grid independence was not reached even for a very fine $2 \mathrm{X}$ grid. The second-order $\frac{1}{2} \mathrm{X}$ grid is seen to provide the same accuracy as the first-order $2 \mathrm{X}$ grid, and grid independence was achieved with the second-order $1 \mathrm{X}$ grid, because the second-order $1 \mathrm{X}$ and $2 \mathrm{X}$ results are essentially identical to each other. It can be seen from these results that at least a second-order CFD method is required for sonic boom simulations. 


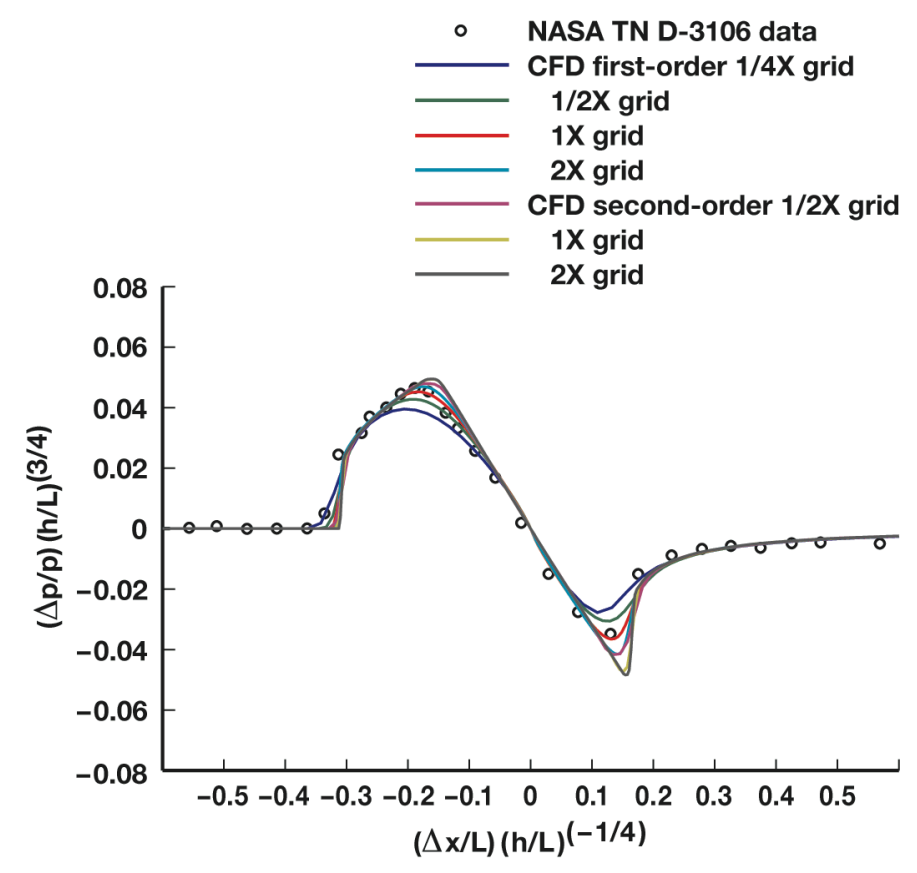

a) Pressure distribution at $\mathrm{h} / \mathrm{L}=5$.

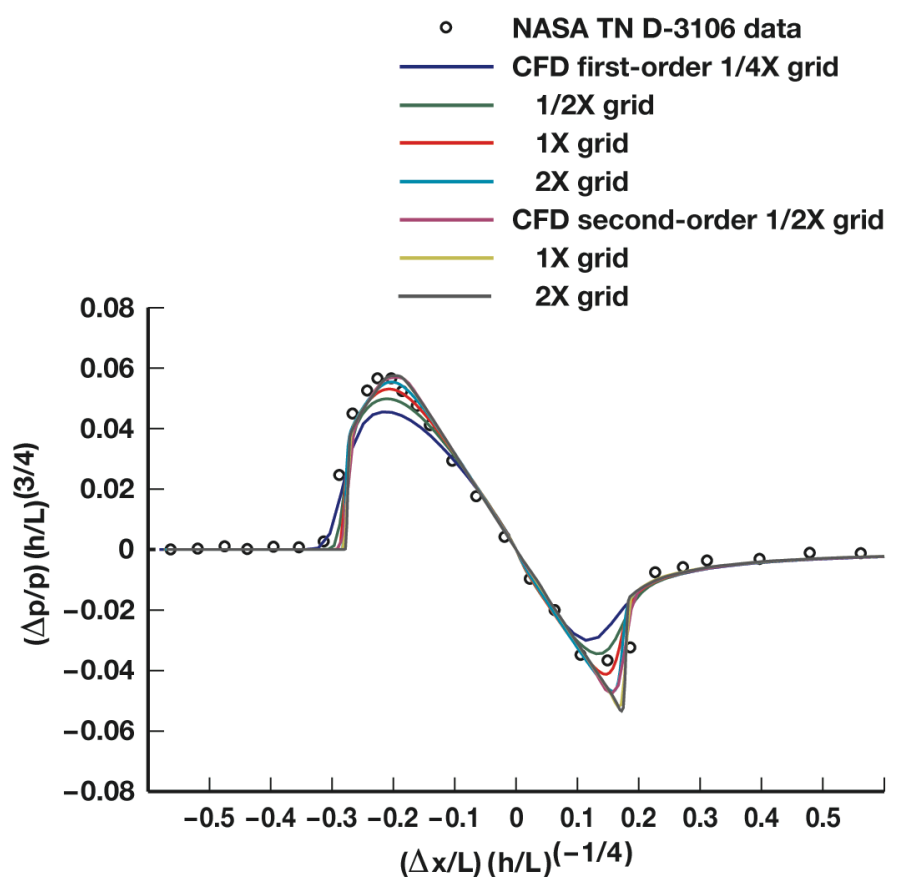

b) Pressure distribution at $\mathrm{h} / \mathrm{L}=10$.

Figure 4. Grid independence study for cone cylinder sonic boom validation test case. 


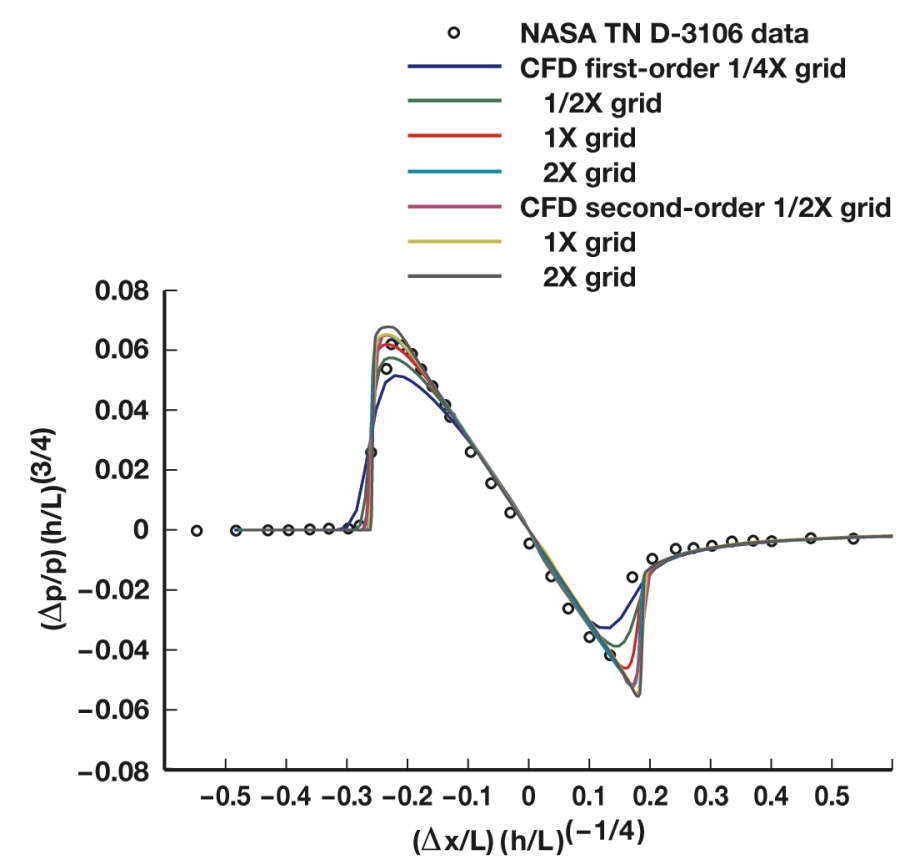

c) Pressure distribution at $\mathrm{h} / \mathrm{L}=\mathbf{2 0}$.

Figure 4. Concluded.

\section{Mach Aligned Approach Compared With Orthogonal Grid Approach}

With the current structured grid CFD approach, one could construct the grid so that it is either inclined such that the grid lines are parallel with the Mach angle of the freestream flow (Fig. 2a) or simply vertical (Fig. 2b). A study was conducted to compare the accuracies of the CFD solutions obtained from these two different structured grid topologies using the same CFD code and spatial order of accuracy (second-order). Figure 5 shows the results.

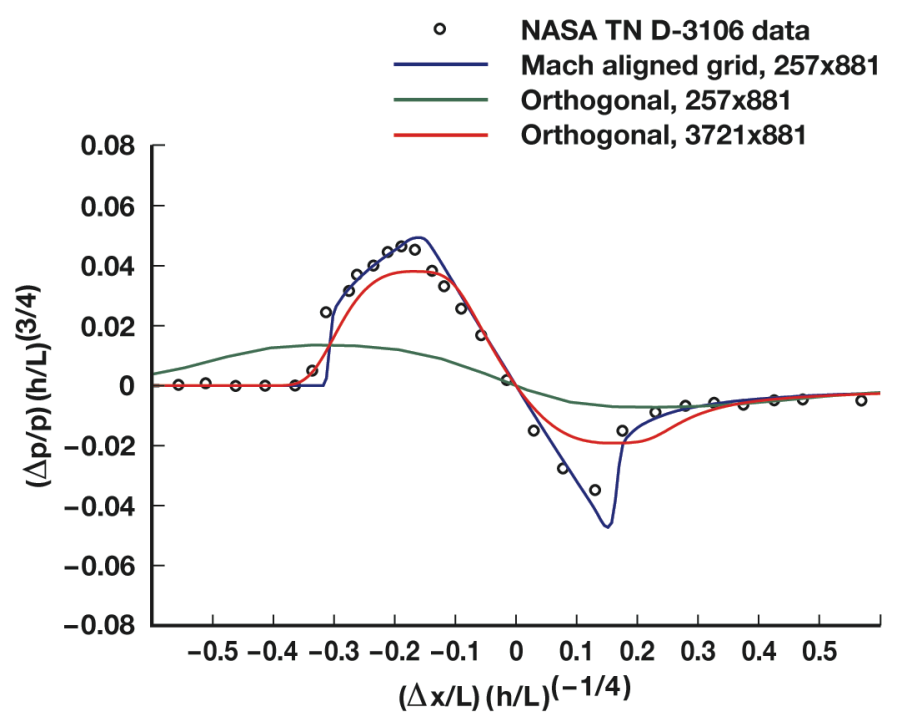

a) Pressure distribution at $\mathrm{h} / \mathrm{L}=5$.

Figure 5. Comparison of Mach aligned grid results with orthogonal grid results. 


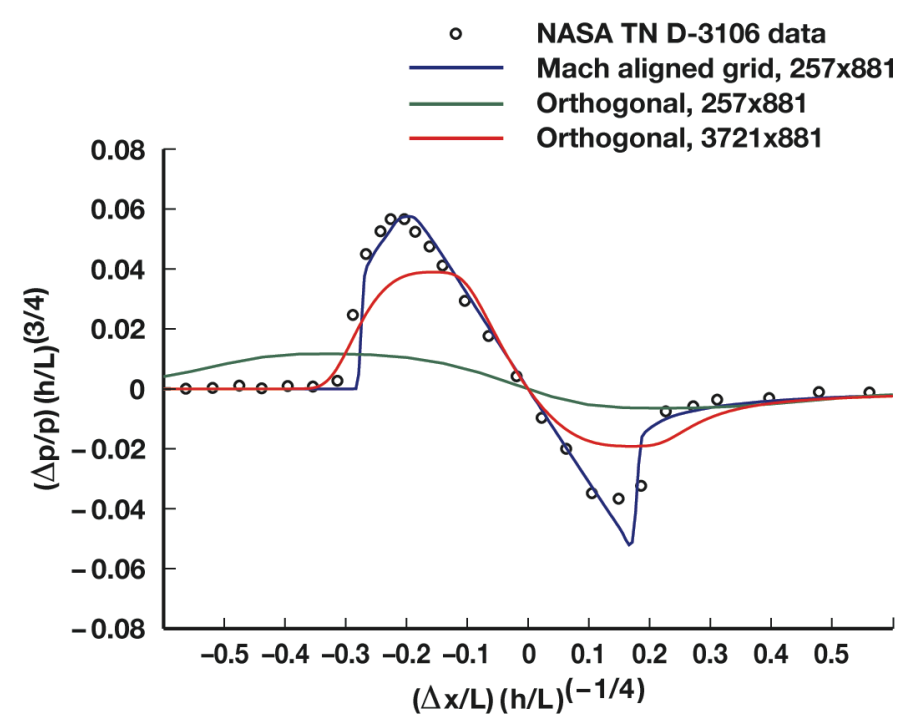

b) Pressure distribution at $h / L=10$.

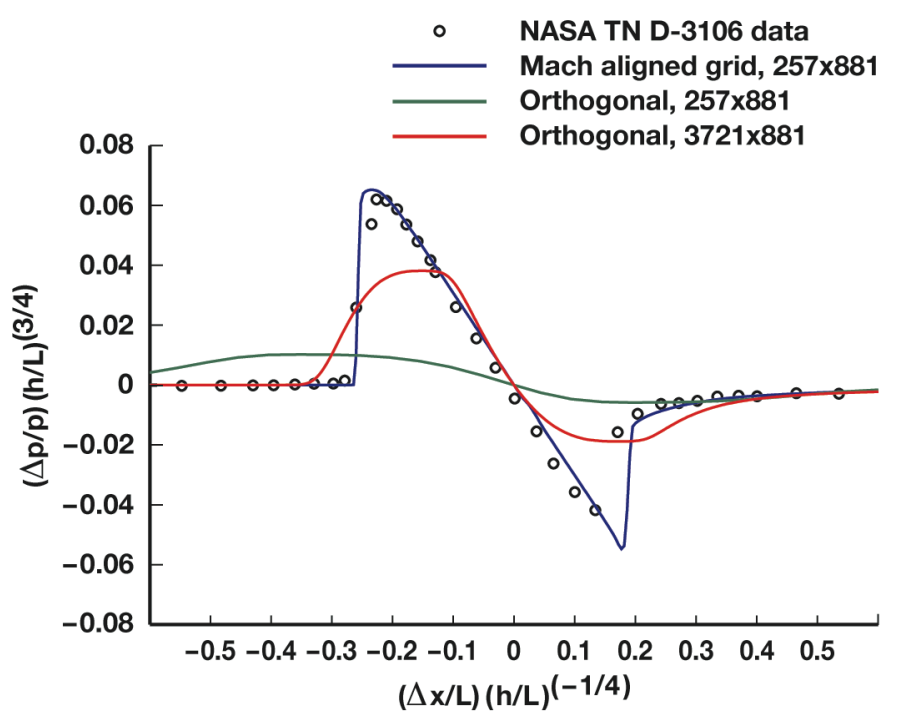

c) Pressure distribution at $\mathrm{h} / \mathrm{L}=\mathbf{2 0}$.

Figure 5. Concluded.

The Mach aligned grid has the same grid size as the second-order 1X grid $(257 \times 881)$, and good agreement exists between the Mach aligned grid results and the experimental data. The sonic boom pressure signatures obtained from the orthogonal grid with the same grid size $(257 \times 881)$, however, are badly dissipated at all three radial distances from the model centerline. Furthermore, the locations of the pressure peaks and dips from the orthogonal grid solution are incorrect.

When the grids in Figs. 2a and $2 \mathrm{~b}$ are compared, it can be seen that although the total grid sizes in the axial direction are identical, the Mach aligned grid concentrates more axial grid points in the $\mathrm{N}$-wave pressure signature than the orthogonal grid. The orthogonal grid has to spread the same number of axial grid points over the entire stream-wise flow domain, whereas the Mach aligned grid concentrates most of the axial grid points within the $\mathrm{N}$-wave sonic boom signature. Therefore, the unfavorable results obtained from the orthogonal grid could have been caused by significantly larger stream-wise grid spacing in the orthogonal grid.

American Institute of Aeronautics and Astronautics 
To determine whether finer stream-wise grid spacing could improve the orthogonal grid results, a fine orthogonal grid was constructed such that the stream-wise grid spacing is the same as the stream-wise grid spacing of the Mach inclined grid. This finer grid spacing increases the number of stream-wise grid points to 3721 for the orthogonal grid. Figure 5 shows that increasing the grid points improves the orthogonal grid results, but the N-wave sonic boom signature for the larger orthogonal grid is still badly dissipated.

To obtain a rough estimate of the approximate number of grid points required for the orthogonal grid to achieve the same level of accuracy as the Mach aligned grid, one could use the grid independence study results shown in Fig. 4. According to Fig. 4a, at an $h / \mathrm{L}$ value of 5 , when the grid size is quadrupled from the second-order $\frac{1}{2} \mathrm{X}$ grid to the second-order $1 \mathrm{X}$ grid, the dip in the normalized $\mathrm{N}$-wave pressure signature drops by approximately 0.006 . As shown in Fig. 5a, the dip in the normalized N-wave pressure signature from the fine orthogonal grid (red line) needs to drop by approximately 0.028 to match the grid independent result from the Mach aligned grid. If the trends in grid refinement are the same for both grid topologies, then one would need to quadruple the orthogonal grid approximately four more times to match the accuracy of the Mach aligned grid.

Because the VULCAN code uses the same cell-centered, finite-volume, upwind CFD algorithm as many popular unstructured compressible CFD codes, the current study shows that one has to be very careful when creating unstructured grids for CFD sonic boom analysis. The isotropic grid cells, such as Cartesian, tetrahedral, and polyhedral cells, favored by many unstructured CFD codes, are very similar to the orthogonal grid topology considered in this report. The current results show that appropriate grid size as well as grid line direction are required for good sonic boom simulations. Even if the approach of solution adaptive mesh refinement were used for unstructured grids, one would still need grid spacing many times smaller than that of the Mach aligned structured grid to achieve similar accuracy. One could also create an unstructured grids aligned to the Mach wave direction. If this approach is used, however, the tetrahedral cells could become highly distorted, and care must be taken to ensure that good CFD solutions could still be achieved.

\section{Viscosity and Turbulence Models}

Full Navier-Stokes computations were performed for comparison with both the Euler computation and the windtunnel test data. The Reynolds number was approximately 500,000 at the end of the test model $(\mathrm{L}=0.0508 \mathrm{~m})$, so the actual flow was most likely transitional. As a result, both laminar and turbulent calculations were performed. For turbulent simulations, the Menter two-equation mode ${ }^{14}$ was used without wall functions. The freestream turbulence intensity and turbulent viscosity ratio were specified to be 0.001 and 0.1 , respectively. Note that the turbulence kinetic energy and dissipation rate were computed from these two parameters, and unphysical solutions in the freestream flow occurred when the freestream turbulence intensity was chosen to be too high.

Care was taken to ensure that the grid spacing remained approximately the same as the Euler computations in the far field inviscid region, while the boundary layers were adequately resolved. The $2 \mathrm{X}(513 \times 1761)$ grid was used both for the laminar and the turbulent calculations. For the laminar computation, grid points were clustered such that approximately 8 grid points and 12 grid points were inside the boundary layers at the cone and the cylinder body, respectively. Previous in-house validation studies with the VULCAN CFD code indicated that the laminar flat plate boundary layer was adequately resolved when at least 6 grid points were inside the boundary layer. Thus the laminar boundary layer should be adequately resolved for the current grid. For the turbulent computation, minimum and maximum wall unit values, $\mathrm{y}^{+}$, for the first grid points off the wall were 1.1 and 4.8 , respectively. Approximately 15 and 25 grid points were clustered inside the boundary layers at the cone and the cylinder body, respectively.

Figure 6 compares the inviscid, laminar, and turbulent CFD results with the wind-tunnel data. The figure shows that the inviscid Euler simulation produces larger extremes in the $\mathrm{N}$-wave pressure signature as discussed previously, and the viscous results give somewhat better agreement with the wind-tunnel data. Near the body at an $h / \mathrm{L}$ value of 5 , significant differences in the tail shock strengths exist between the inviscid, laminar, and turbulent models. The laminar model gives the best agreement with the wind-tunnel data at an $h / \mathrm{L}$ value of 5 . Farther away from the body at an $h / \mathrm{L}$ value of 20 , there is essentially no difference between the laminar and turbulent models, and both predict a tail shock pressure differential that is 18 percent less than that of the inviscid model, in better agreement with the wind-tunnel data. From the results of this study, it can be seen that somewhat better agreement with the wind-tunnel data could be obtained from a full Navier-Stokes simulation, even for this very simple validation test case. 


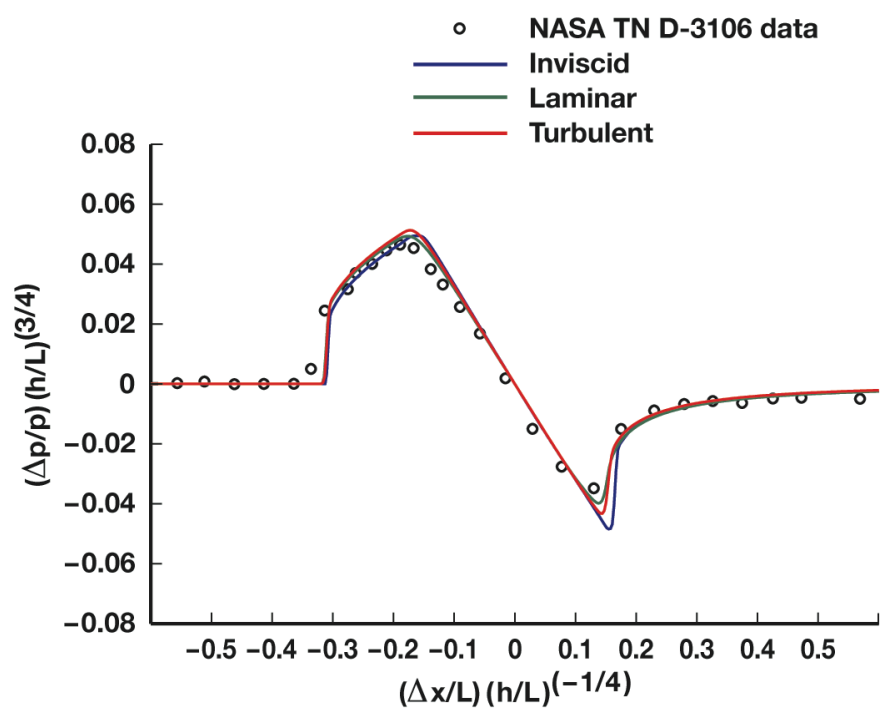

a) Pressure distribution at $h / L=5$.

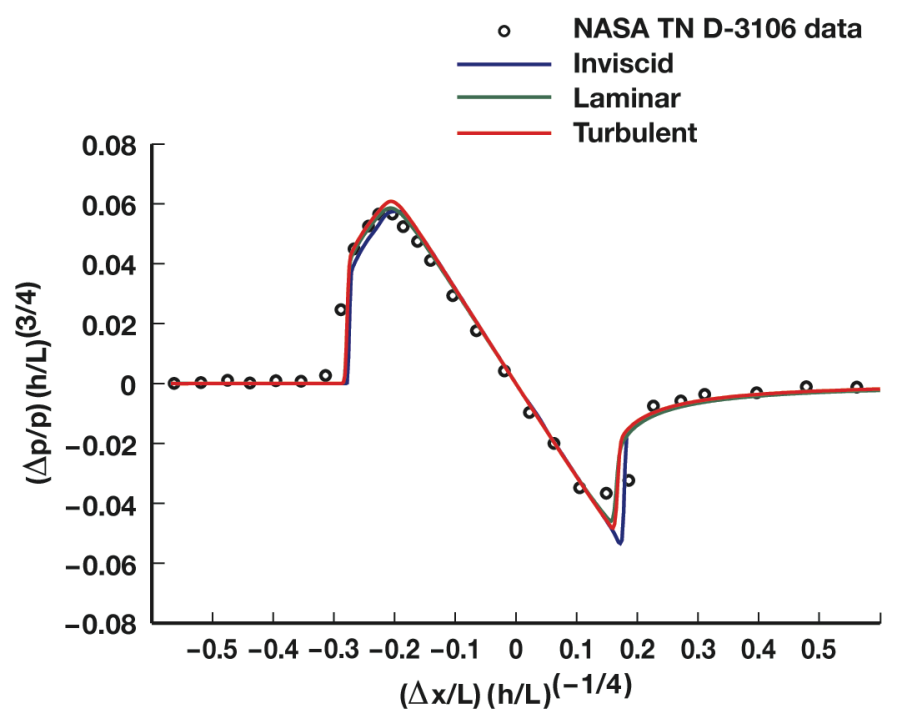

b) Pressure distribution at $\mathrm{h} / \mathrm{L}=10$.

Figure 6. Viscosity and turbulence effects on sonic boom signatures. 


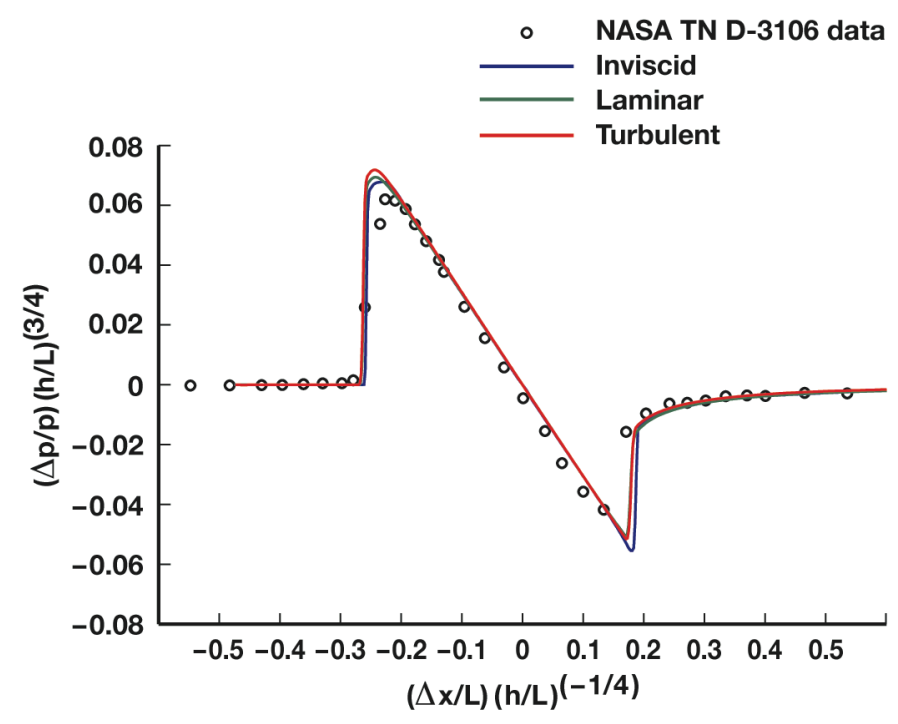

c) Pressure distribution at $h / L=20$.

Figure 6. Concluded.

\section{Axisymmetric Nozzle Analysis}

The results of the study presented in section II show that the VULCAN CFD code can be highly accurate in sonic boom propagation studies provided the appropriate grid topology, grid spacing, and numerical order of accuracy are used. To examine the jet plume effects on the sonic boom signature of a supersonic aircraft, a simplified axisymmetric nozzle geometry, representative of the nozzle on the NASA Dryden NF-15B LaNCETS research aircraft, is studied.

\section{A. Jet Plume Shock-Sonic Boom Interaction Flow Physics}

Figure 7 illustrates the primary flow physics present in the interaction between the exhaust jet plume shock and the sonic boom coming off of an axisymmetric body in supersonic flight. Normally the bow shock (blue line) and the tail shock (green line) form the characteristic N-wave of the sonic boom. When the nozzle exhaust flow is underexpanded (increased nozzle exit static pressure caused by increasing the nozzle total pressure or decreasing the nozzle exit area, or both), the nozzle exit static pressure is higher than the ambient static pressure. As a result, the jet plume boundary opens wider, and the plume shock angle increases. When the plume shock angle increases, the plume shock intercepts the expansion wave in the middle of the N-wave earlier than the normal tail shock, reducing the dip of the sonic boom N-wave signature. Note that vectoring the nozzle plume downwards also produces the same effects as the plume under expansion. Considering the flow physics involved, one would expect that perfectly expanded and overexpanded nozzle flow, as well as vectoring the nozzle plume upwards, should produce little or no reduction in the tail shock strength and the dip of the sonic boom $\mathrm{N}$-wave signature, because the plume shocks for these cases do not intercept the expansion wave earlier than the normal tail shock.

Although the aforementioned simple flow concept is useful for visualizing the initial jet plume shock-sonic boom interaction, it does not provide any information on the shock train or structure downstream of the initial tail shock. A full CFD simulation would be required to answer this question. 


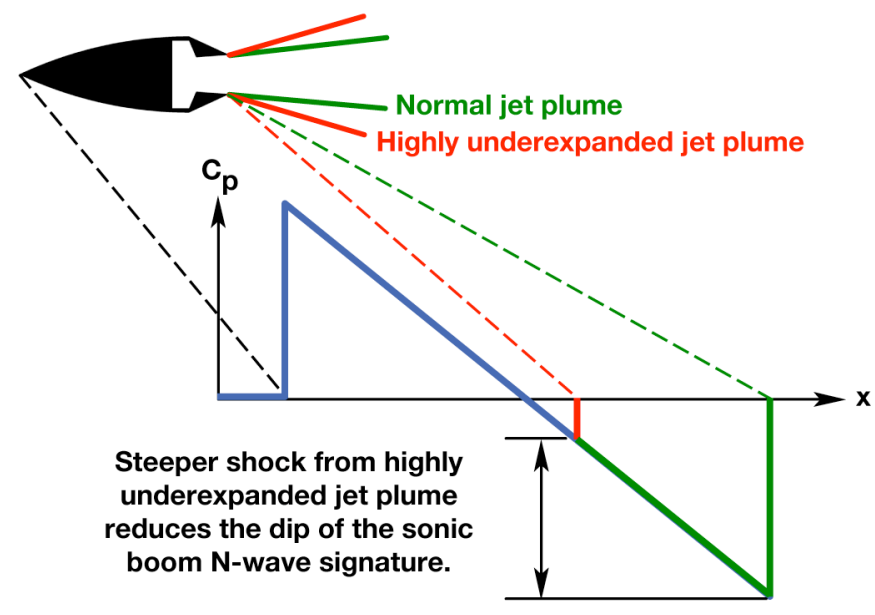

Figure 7. Jet plume shock-sonic boom interaction flow physics.

\section{B. Analysis Description}

To study the detailed flow physics of the interaction between the jet plume and the sonic boom signature, a CFD analysis was conducted. The full analysis approach, including the simplified axisymmetric nozzle geometry, grid topology, boundary conditions, initial conditions, and flow solver settings are described.

\section{Simplified F-15 Nozzle Geometry}

Because the primary objective in the current research was to study the detailed flow physics of the interaction between the jet plume and the sonic boom signature, an axisymmetric approximation was used. The airplane was not modeled, so the nozzle plume flow could be resolved in greater detail. Despite the simplification, results obtained from this axisymmetric nozzle study would still be useful for the proper modeling of the nozzle plume flow field in any follow-on full-aircraft CFD work. Figure 8 illustrates the axisymmetric simplification used in the current research. A tangent ogive with approximately the same length and radius as that of the NF-15B radome was used upstream of the axisymmetric nozzle to produce the characteristic $\mathrm{N}$-wave for the sonic boom signature. The internal nozzle geometry was modeled from the LaNCETS phase I, flight number 2, signature 3 aircraft operating conditions. The nozzle area ratio was 1.308 with straight convergent and divergent sections.

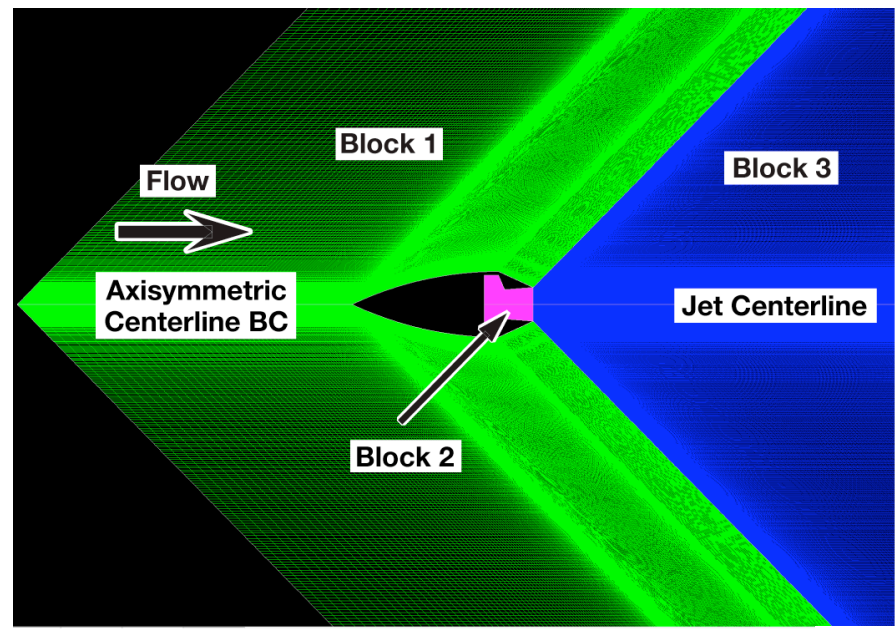

Figure 8. Simplified axisymmetric nozzle geometry used in current analysis.

\section{Grid Topology}

Figure 9 shows the grid topology used in this CFD code validation study. Axisymmetric structured grid topology was used in the calculations. Three grid blocks were used to model the flow domain: external flow (block 1, green), 
internal nozzle flow (block 2, pink), and jet plume flow (block 3, blue). Grid lines were aligned in the Mach wave direction to achieve the best solution quality as presented in section II. A grid line was purposely placed at a radial distance of $21.34 \mathrm{~m}(30 \mathrm{D})$ from the centerline (the average distance of the aircraft sonic boom signature collected from flight), so that the sonic boom pressure signature at this location could be obtained from the CFD solution without the need for additional interpolation.

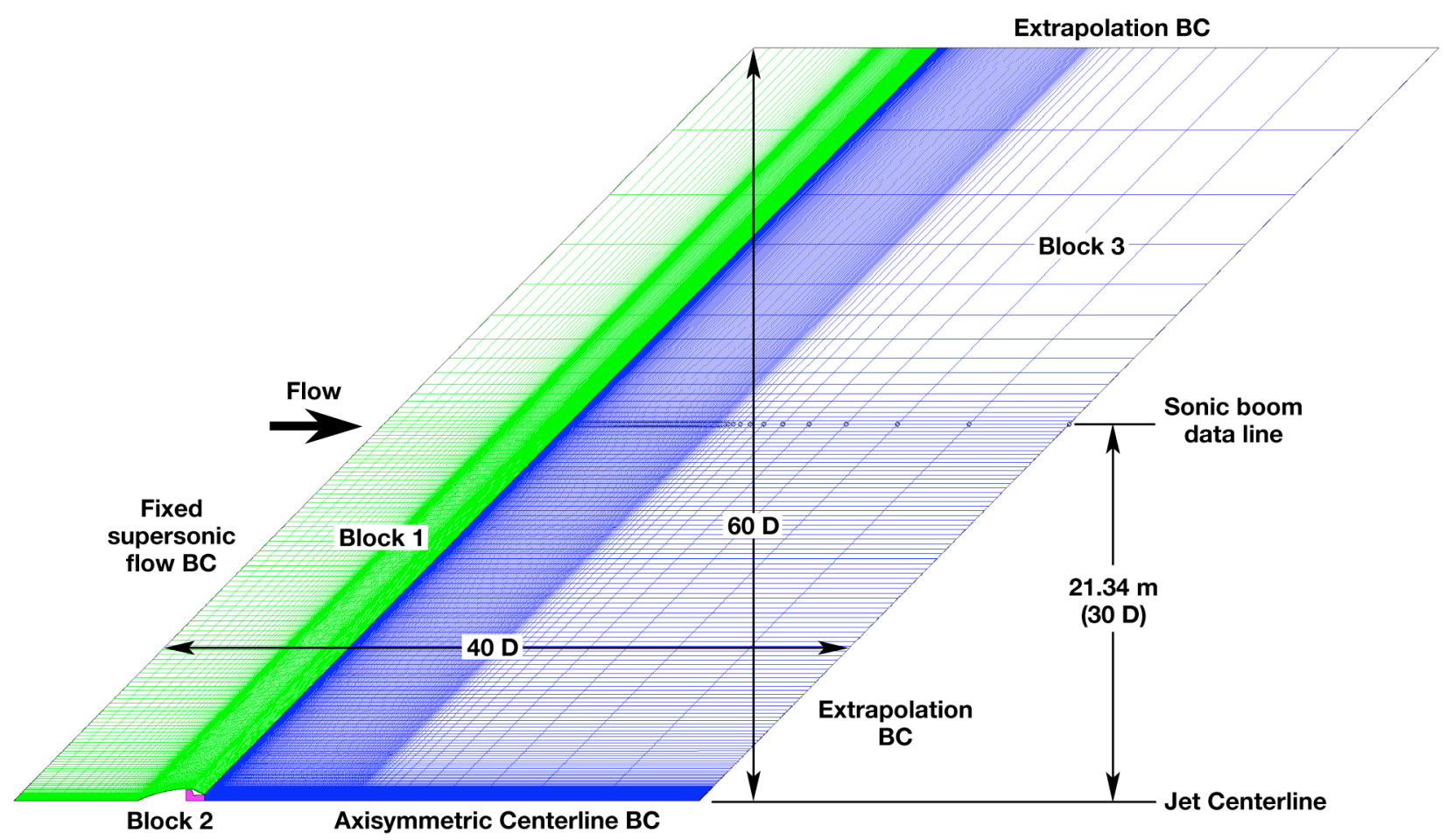

Figure 9. Computational fluid dynamics (CFD) grid topology for axisymmetric nozzle CFD simulations.

\section{Boundary Conditions and Initial Conditions}

Figure 9 summarizes the BCs used in the current study. Fixed supersonic inflow BC was used at the inflow (left) boundary. To match the flight conditions for LaNCETS phase I, flight 2, sonic boom signature 3, the following freestream inflow conditions were specified in the CFD simulations: Mach number of 1.4, static pressure of $18.66 \mathrm{kPa}$, and static temperature of $216.6 \mathrm{~K}$. The internal nozzle flow was modeled from the start of the convergent section with a total pressure of $180.6 \mathrm{kPa}$ and total density of $0.5649 \mathrm{~kg} / \mathrm{m}^{3}$. The resulting NPR value is 9.7 , matching the nominal nozzle operating condition of the flight experiment. Zeroth-order extrapolation was used for the downstream (right) and far field (top) boundaries. First-order linear extrapolation BC was also evaluated on the downstream and far field computational boundaries but did not have any effect on the CFD solutions. Axisymmetric centerline BC was used to model the axis of symmetry upstream of the nose tip, centerline of the nozzle, as well as the centerline of the jet plume. Finally, a no-slip wall was used to model both the bullet body and the nozzle's internal wall.

\section{Computational Fluid Dynamics Solver Settings}

Axisymmetric CFD simulations were conducted using the VULCAN finite-volume, structured CFD code. The calorically perfect gas model was used with a ratio of specific heats value of 1.4 and a specific gas constant value of $287 \mathrm{~J} /(\mathrm{kg} \mathrm{K})$ in both the freestream and the internal nozzle flow. The CFD code validation study showed that viscous CFD simulations improved the comparison with the experimental wind-tunnel data. Therefore, full NavierStokes viscous computations were performed for all of the studies discussed in this section. Because the Reynolds numbers are very high for the flight condition considered (approximately 150 million based on external freestream flow and aircraft length, and 23 million based on the internal nozzle flow and nozzle exit diameter), the Menter twoequation turbulence model without wall function was used to simulate turbulent flows both inside the nozzle and in the external flow. The boundary layers are very well resolved with the current grid. Minimum and maximum $y^{+}$ 
values for the first grid points off the wall are 0.0077 and 0.67 , respectively. The inviscid flux terms were discretized using the LDFSS scheme. The second-order $(\kappa=1 / 3)$ MUSCL flux interpolation method was used, because it was found to provide superior accuracy over the first-order method in the code validation study. The van Leer TVD flux limiter was used in connection with the second-order method. To accelerate the iterative convergence, grid sequencing was used on three coarse grid levels. The simulations were considered converged when the L2 norm of the residuals became constant as a function of iterations. Figure 10 shows a sample residual history. Ten thousand iterations were performed on each of the three coarse grid levels. Nearly 20,000 additional iterations were needed to drive the finest grid solution to final convergence in this full Navier-Stokes turbulent simulation. Local time stepping was used to accelerate convergence to a steady-state solution. The CFL number was ramped up from 0.01 to 1.5 in 5000 iterations for each of the coarse grid sequences and 0.01 to 0.5 in 5000 iterations for the final fine grid. The CFL numbers were smaller than the validation CFD runs to avoid spurious pressure oscillations in the jet plume.

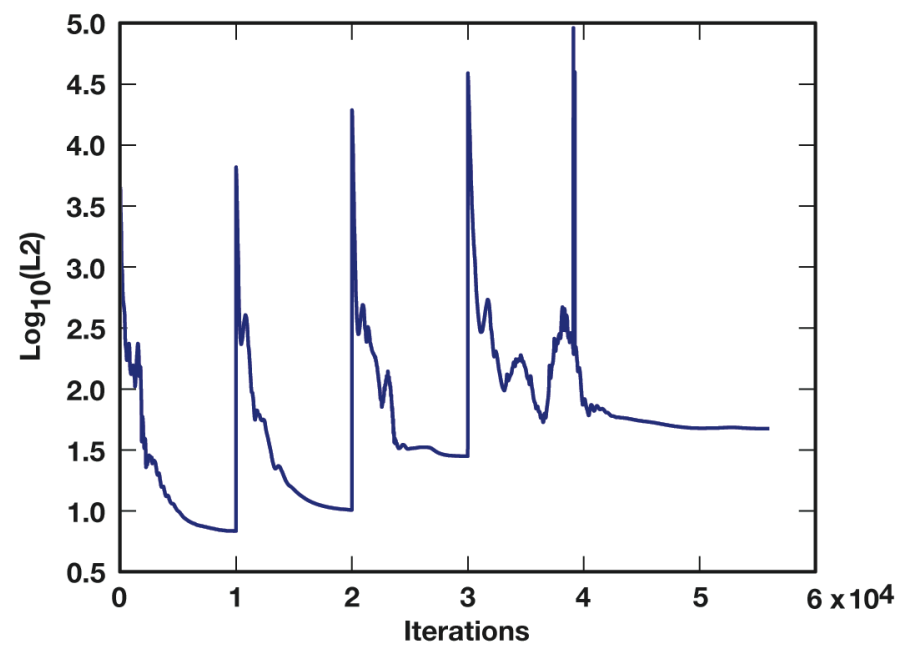

Figure 10. Typical residual history for axisymmetric nozzle computational fluid dynamics simulations.

\section{Grid Independence Study}

A grid independence study was conducted to determine the minimum grid size required for grid independence solutions. The grid sequencing feature of the VULCAN CFD code was used to conduct the grid independence study. Four different grid levels were used for grid sequencing. The converged solutions from the three finest grid levels were used for the grid independent study: $2 X(577 \times 577,385 \times 193,577 \times 769)$, double; $1 X(289 \times 289,193 \times 97$,

$289 \times 385)$, normal; and $\frac{1}{2} X(145 \times 145,97 \times 49,144 \times 193)$, half. For the flow under consideration, grid independence must be studied not just at one location in the flow but for several different major flow features. The nozzle internal flow affects the jet plume. The jet plume in turn influences the external upstream flow over the boat tail (aft) section of the bullet body through the boundary-layer feedback mechanism. Both the jet plume and bullet body flows affect the far field sonic boom signature. Therefore, it is important to separately examine the grid independence of each of these major flow features.

Figure 11 shows the grid independence study results. The pressure distributions at four different locations are examined: the far field sonic boom pressure signature at $21.34 \mathrm{~m}$ above the jet centerline (Fig. 11a), the wall static pressure distribution over the bullet body (Fig. 11b), the jet plume centerline pressure (Fig. 11c), and the internal nozzle wall pressure (Fig. 11d). It can be seen that grid independent results are essentially achieved for the far field sonic boom signature, the flow over the bullet body, and the internal nozzle flow. The jet centerline pressure distributions in Fig. 11c still show significant differences at the second plume shock (approximately $x=5 \mathrm{~m}$ ), indicating that grid independence has not been reached for the jet plume flow. These differences do not seem to affect the far field sonic boom results, however, as shown in Fig. 11a. Because the far field sonic boom is the primary focus of this report, the $2 \mathrm{X}$ grid was used for all subsequent studies. 


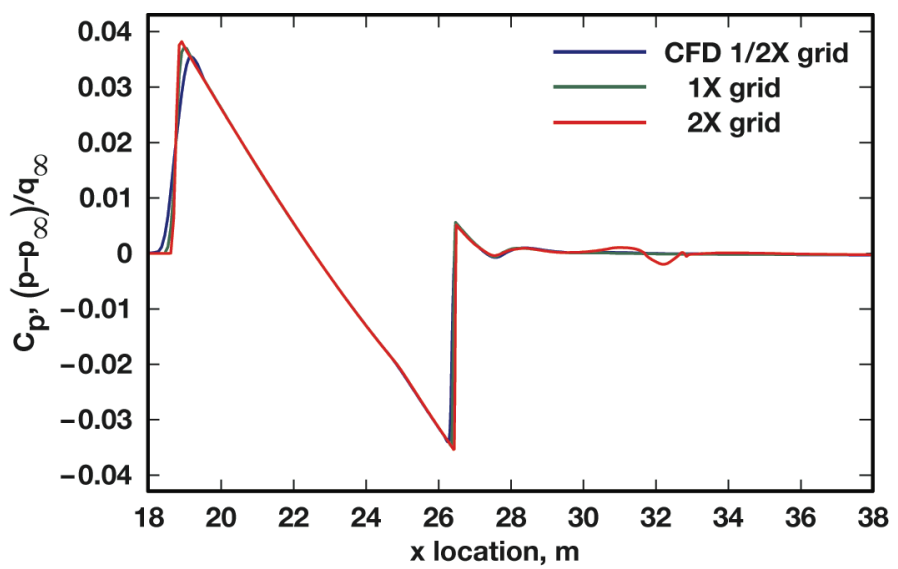

a) Sonic boom pressure signature $21.34 \mathrm{~m}$ from jet centerline.

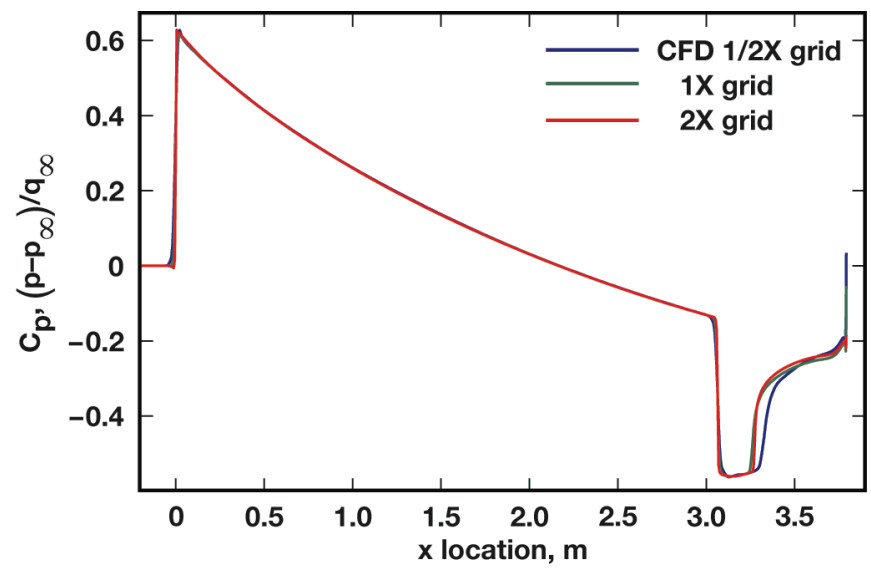

b) Bullet body wall static pressure.

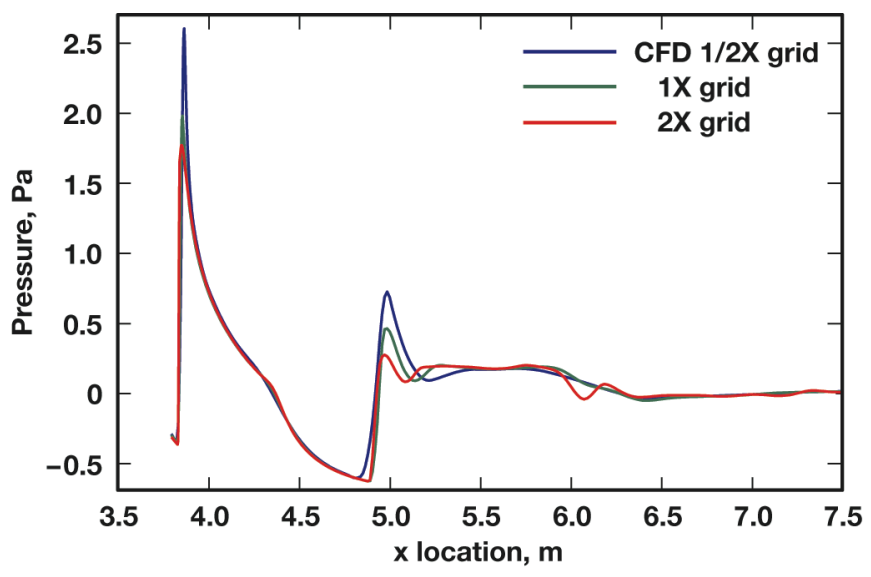

c) Jet plume centerline static pressure.

Figure 11. Grid independence study for axisymmetric nozzle computational fluid dynamics simulations; nozzle pressure ratio of 9.7. 


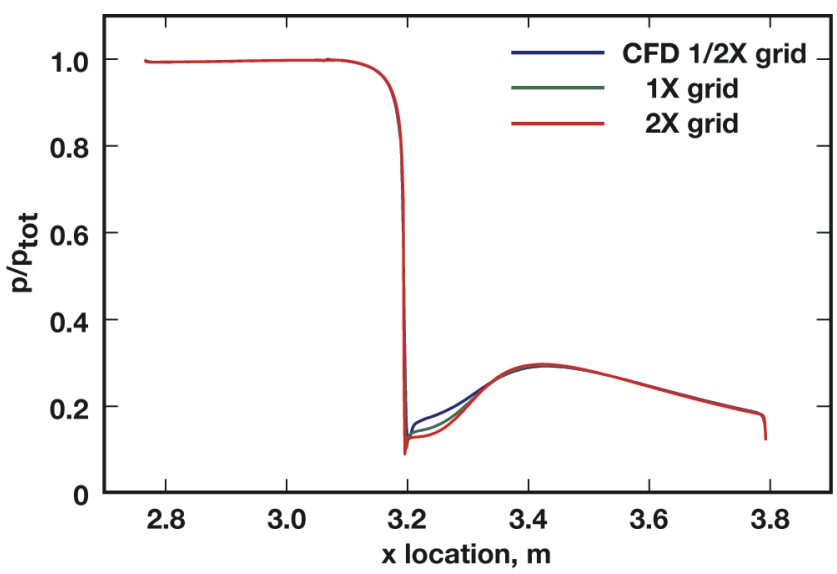

d) Internal nozzle wall pressure.

Figure 11. Concluded.

An important discrepancy is noted from examining Fig. 11a. The LaNCETS phase I, flight number 2, signature 3 sonic boom probing data, as seen in Fig. 12, shows an extensive shock train after the sonic boom tail shock at a distance of $36.5 \mathrm{~m}$ back from the NF-15B nose (without the nose boom), consisting of three, perhaps four or five shocks. Yet the axisymmetric CFD solution in Fig. 11a, obtained using the same flight condition and NPR value as those used in the flight experiment, does not show any sonic boom tail shock trains. This discrepancy is examined further in the next section.

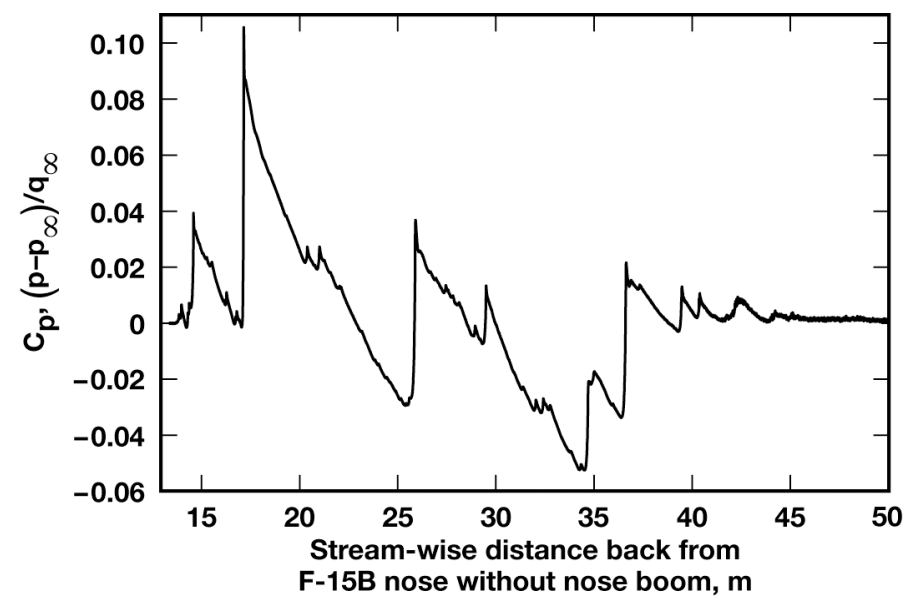

Figure 12. Flight-measured sonic boom pressure signature from Lift and Nozzle Change Effects on Tail Shock (LaNCETS), phase I, flight 2, signature 3.

\section{Effects of Imperfectly Expanded Jet Plume}

The NPR is defined as the ratio between the nozzle total pressure and the freestream static pressure, and it is an important parameter in nozzle performance analysis. For an installed engine nozzle, the nozzle exit flow is actually exposed to the local ambient static pressure and not the freestream static pressure. The presence of the airplane will cause the local ambient static pressure in the vicinity of the jet nozzle to be different from the freestream static pressure, which causes the nozzle to operate under an effective NPR value that is different from the nominal value computed from the freestream static pressure. Although a complete aircraft was not modeled in the present study, the effect of changes in the local ambient pressure on the resulting jet plume and sonic boom pressure signature could still be examined by varying the freestream static pressures in the present CFD simulations.

Five different CFD simulations were conducted: no jet with blunt base, perfect expansion, and NPR values of 3.9, 9.7, and 25.2. For the no jet case, the nozzle exit plane was modeled as a no-slip surface, and no jet was emanating from the nozzle exit, resulting in a simple blunt-base projectile flow. The actual jet plume also was not modeled in the perfect expansion case. The perfectly expanded flow was simulated by having a horizontal 
inviscid-wall computational boundary extending from the nozzle lip at the end of the bullet body's boat tail to the downstream computational boundary. For the jet plume calculations, the ambient pressure values of 46.56, 18.66, and $7.172 \mathrm{kPa}$ (corresponding to pressure altitudes of $20,000,40,000$, and $60,000 \mathrm{ft}$, respectively) were used. A constant nozzle total pressure of $180.6 \mathrm{kPa}$ was used for all jet plume calculations, resulting in nominal NPR values of 3.9, 9.7, and 25.2, respectively. For the current nozzle area ratio of 1.308 and specific heats ratio of 1.4, perfect expansion of this nozzle requires an NPR value of 4.7. Thus the LaNCETS flight NPR value of 9.7 was actually underexpanded.

Figure 13 shows the simulated shadowgraph visualizations from the CFD solutions. The contours of the Laplacian of the flow density are shown in gray scales to simulate the shadowgraph visualization technique. For the no jet case, the flow field shown in Fig. 13a is representative of the flow over a supersonic blunt-base projectile with a bow shock, expansion fan, and tail shock (for example, see reference 15). The tail shock is actually a coalescence of three different oblique shocks emanating from the oblique shock-shear layer interaction. The expansion fan at the start of the boat tail can also be seen in this figure. A flow separation region starts near the middle of the boat tail. Although the inviscid flow features are fairly realistic in this simulated shadowgram, the turbulent wake flow off the base of the projectile lacks the irregular, small-scale turbulent eddies seen in real shadowgrams of similar supersonic projectile flows. ${ }^{15}$ The Reynolds-averaged Navier-Stokes approach used in the current CFD simulations model the time-averaged equations, and as a result, will not capture small-scale turbulent eddies. Instead a higher-level CFD approach, such as a large eddy simulation (LES) or detached eddy simulation (DES), is needed.

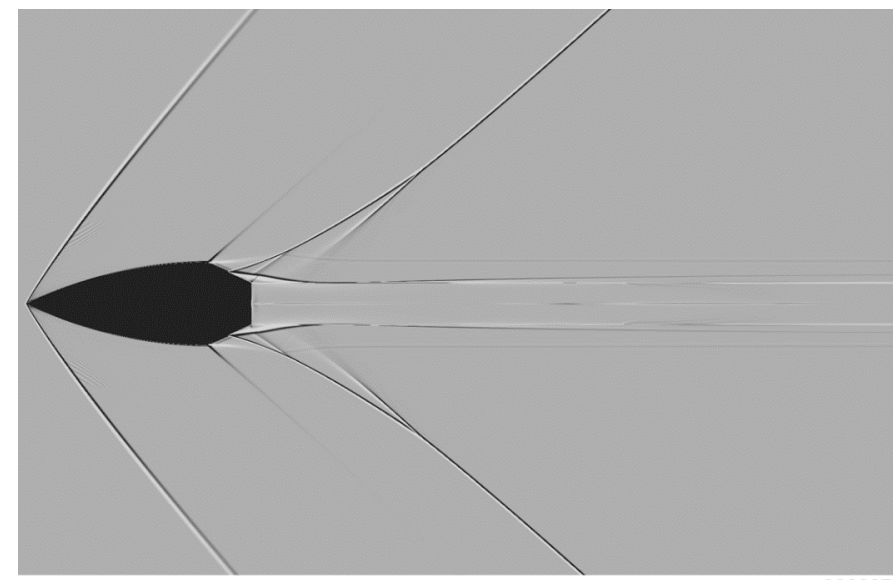

a) No jet.

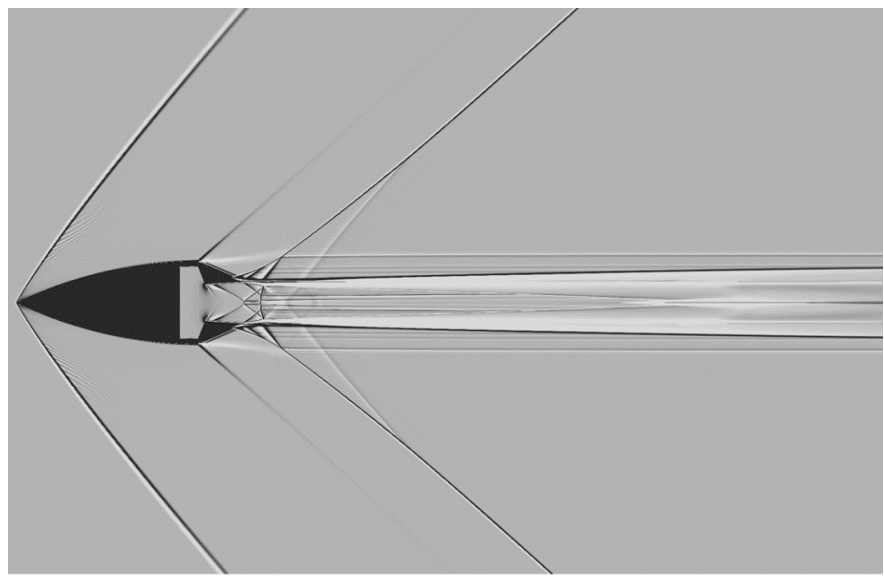

b) Nozzle pressure ratio of 3.9.

Figure 13. Simulated shadowgraph visualizations; imperfectly expanded jet plume effects. 


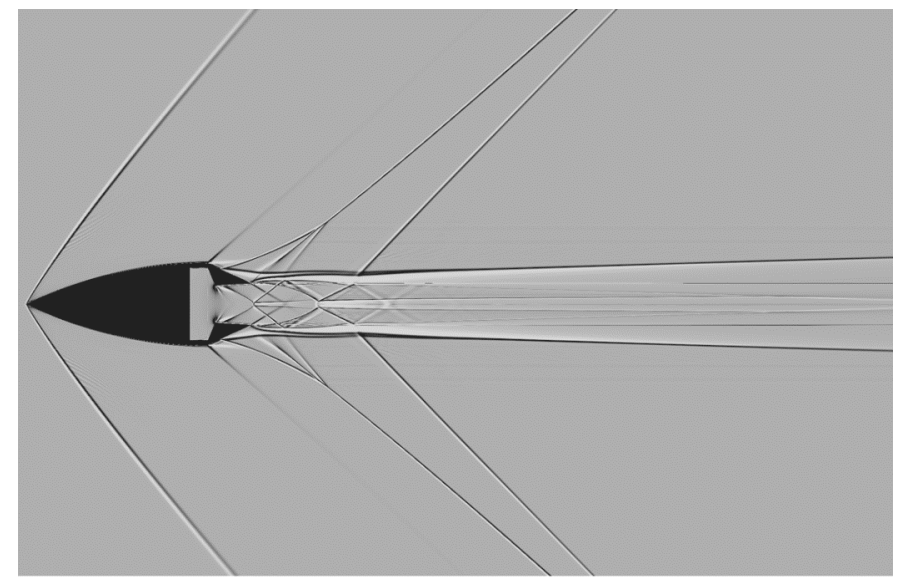

c) Nozzle pressure ratio of 9.7 .

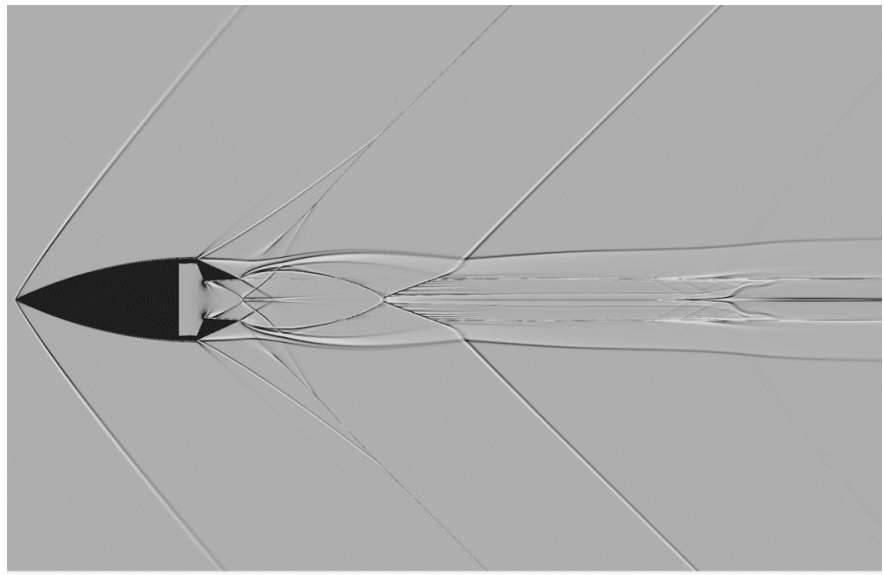

d) Nozzle pressure ratio of 25.2.

Figure 13. Concluded.

The overexpanded nozzle plume, at an NPR value of 3.9, is visualized in Fig. 13b. Because the local ambient static pressure is higher than the jet static pressure at the nozzle exit, the jet plume contracts slightly at the nozzle exit plane. A small flow separation bubble near the nozzle lip is observed. A complicated shock structure is seen in both the internal nozzle flow and the jet plume. Because the nozzle's divergent wall is straight, the flow in the nozzle's divergent section is nonisentropic, and oblique shocks are seen emanating from the nozzle's divergent walls. Unlike the aforementioned blunt-base flow, the tail shock is now a coalescence of four different shocks: three from the oblique shock-shear layer interaction at the end of the body's boat tail, and one from inside the plume. Note that the shock train in the plume coalesces into a single tail shock in the far field sonic boom for this case. Thus shock trains inside the jet plumes do not automatically become shock trains in the far field sonic boom pressure signature.

The underexpanded nozzle plumes, at NPR values of 9.7 and 25.2, are visualized in Figs. 13c and 13d, respectively. Because the local ambient static pressure is lower than the jet static pressure at the nozzle exit, the jet plume expands at the nozzle exit. Flow separation is observed over most of the boat tail region for an NPR value of 9.7. At an NPR value of 25.2, the flow is completely separated over the boat tail region. Similar to the overexpanded CFD solution, a complicated shock train forms inside the jet plume, starting from inside the nozzle. The shock train in the plume at an NPR value of 9.7 eventually coalesces into a single sonic boom tail shock. The extra shocks from the jet plume downstream of the tail shock at an NPR of 25.2, however, no longer coalesce into the sonic boom tail shock as in the previous cases but remain distinct from the tail shock and eventually form a shock train in the far field sonic boom signature. 
Figure 14 shows a comparison of the jet plume shapes. The outlines of the jet plumes were created from the CFD solutions by tracing a streamline from the nozzle lip downstream of the boat tail. In the no jet and overexpanded cases, the jet plumes are parallel after the initial perturbation near the nozzle exit, and no additional shocks are produced beyond the tail shock. In the underexpanded cases, the jet plumes expand and contract downstream of the nozzle exit, causing additional shocks to form downstream of the tail shock.

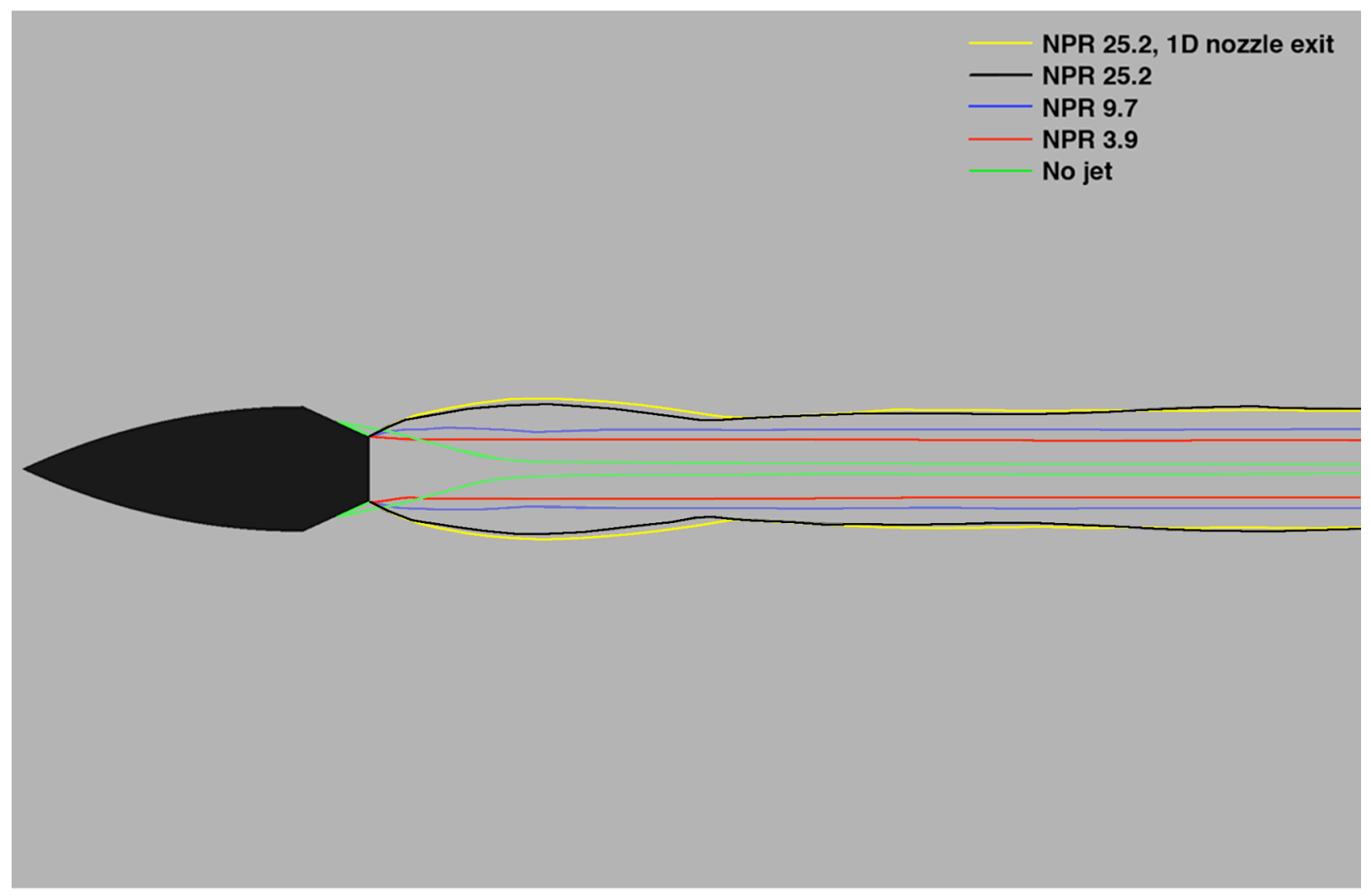

Figure 14. Comparison of jet plume shapes.

Figure 15 shows the static pressure distributions over the bullet body, jet plume centerline, and far field sonic boom signature $21.34 \mathrm{~m}$ from the jet plume centerline. As expected, the front shock in the $\mathrm{N}$-wave sonic boom signature (Fig. 15c) is identical for all cases. The strength of the tail shock in the $\mathrm{N}$-wave, however, depends on the state of the jet plume. The tail shock is strongest (worst) for the case of no jet with a blunt base, and the tail shock strength is reduced when the jet plume is present. When the plume is overexpanded, perfectly expanded, or mildly underexpanded, the tail shock pressure rise is reduced by approximately 14 percent from the no jet case. When the plume is highly underexpanded (at an NPR value of 25.2), the tail shock pressure rise is reduced by approximately 42 percent from the no jet case. Note that the tail shock pressure rise in the far field sonic boom signature on the ground might not be reduced as much because of possible shock coalescence of the tail shock train observed in Fig. 15c. In general, the trend of reducing tail shock strength in the sonic boom signature for increasing NPR values agrees with the findings in reference 8.

As discussed previously, the LaNCETS phase I flight data showed a distinctive tail shock train at a nominal NPR value of 9.7 at approximately the same distance from the jet centerline. The CFD solution at this NPR value, however, does not show any shock trains. The only CFD case in which a tail shock train is present is at an NPR value of 25.2. A possible explanation for this apparent discrepancy is that the actual ambient static pressure at the base of the aircraft is lower than the freestream static pressure. Because the NPR value is defined as the ratio of the nozzle total pressure to the freestream static pressure, the aircraft nozzles, exposed to a local ambient static pressure (at the base of the aircraft) that is lower than the freestream static pressure, were actually operating at a much higher effective NPR than the nominal value indicates. A full-aircraft CFD simulation must be conducted to examine this issue in more detail. 


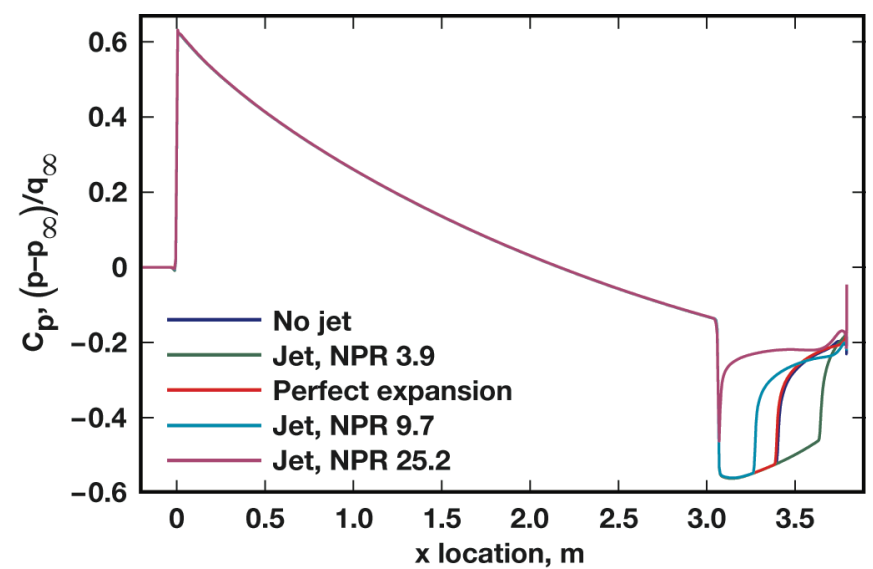

a) Bullet body wall static pressure.

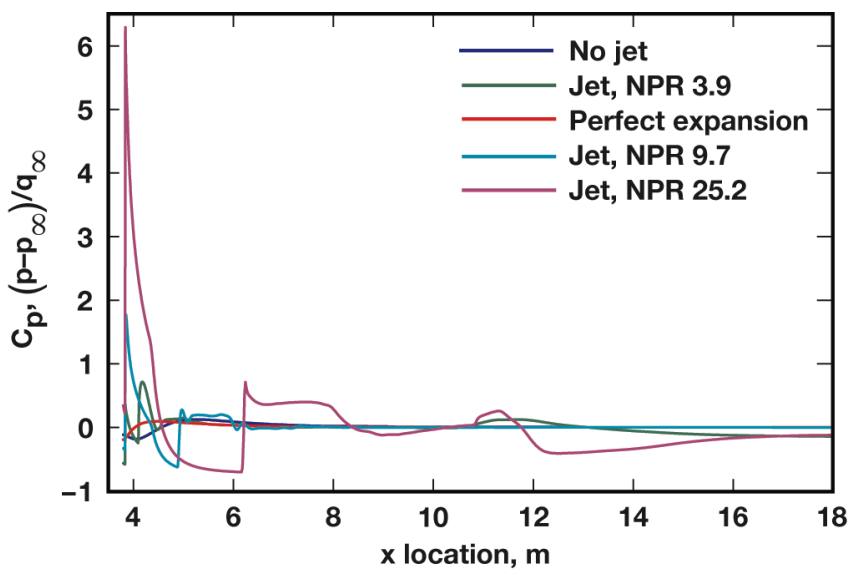

b) Jet plume centerline static pressure.

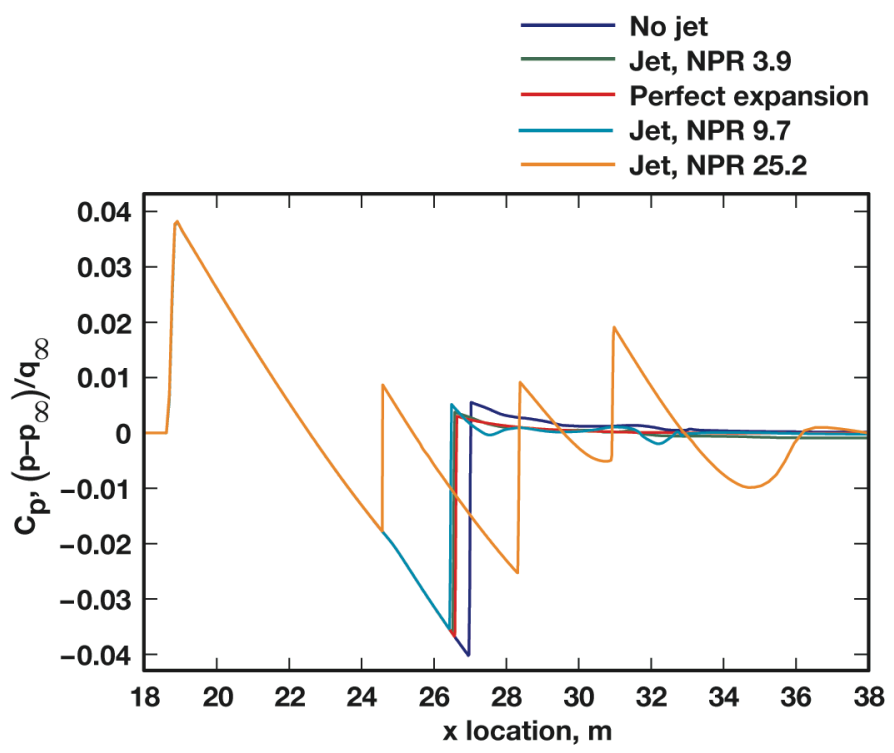

c) Sonic boom pressure signature $21.34 \mathrm{~m}$ from jet centerline.

Figure 15. Effects of imperfectly expanded jet plumes. 


\section{E. One-Dimensional Flow Effects}

Some full-aircraft three-dimensional CFD simulations use the 1D approximation in modeling the nozzle jet exhaust flows. With this approximation, the flow across the nozzle throat or exit plane is specified to be constant using values computed from the 1D isentropic nozzle theory. As shown in Fig. 13, however, the flow inside the real nozzle is multidimensional with a complex shock structure. To study the effects of the popular 1D nozzle approximations on the far field sonic boom predictions, CFD simulations were conducted with uniform flow conditions, computed from isentropic 1D flow properties specified at the nozzle throat and exit planes, used as BCs.

Figure 16 provides the simulated shadowgraph visualizations of the CFD solutions for an NPR value of 25.2. Figures 16a, 16b, and 16c show the full-axisymmetric, 1D nozzle throat, and 1D nozzle exit solutions, respectively. It can be seen that although the 1D nozzle plumes look similar to the full-axisymmetric plume, important flow features are either incorrectly captured or missing as compared with the full-axisymmetric nozzle solution. The oblique shocks originating from inside of the full-axisymmetric nozzle are incorrectly captured in the 1D nozzle throat solution. The 1D nozzle exit solution does not have any internal nozzle shocks at all. The 1D nozzle tail shock, for both the 1D throat and nozzle exit cases, is a coalescence of only two shocks, not three as in the case of the full-axisymmetric simulations. Also, the second plume shock (shown as a faint dark line on the right in Fig. 16a) is not captured by either of the 1D approaches. Finally, the 1D plumes expand slightly more than the fullaxisymmetric plume.

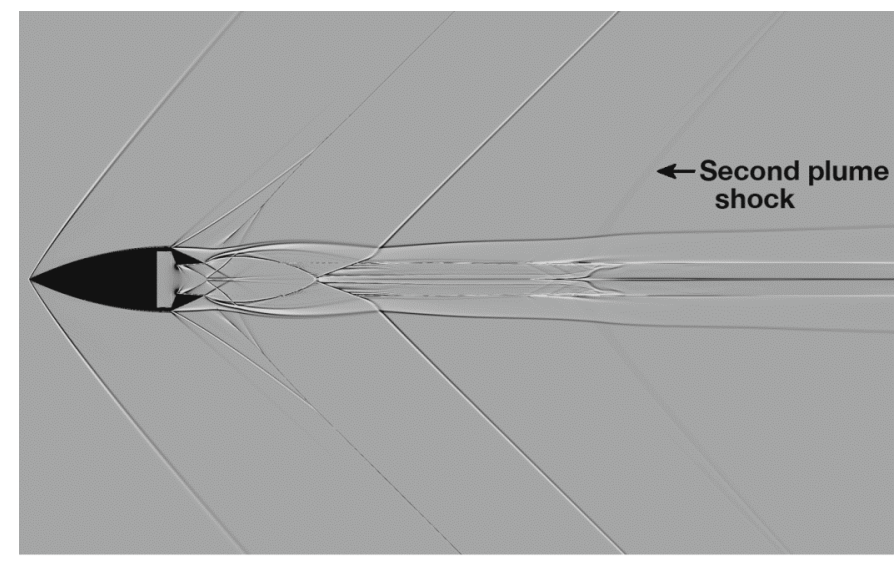

a) Full axisymmetric nozzle.

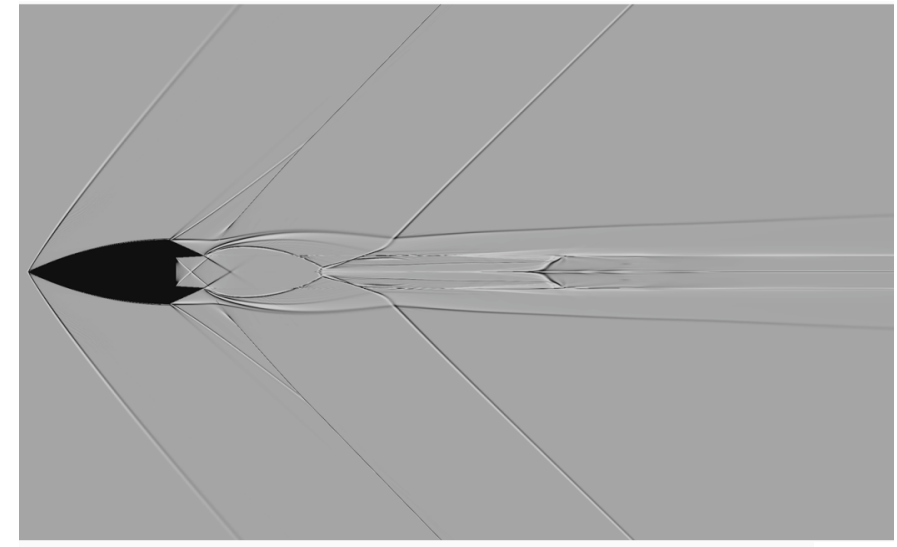

b) One-dimensional nozzle throat.

Figure 16. Simulated shadowgraph visualizations; one-dimensional nozzle flow; nozzle pressure ratio of 25.2. 


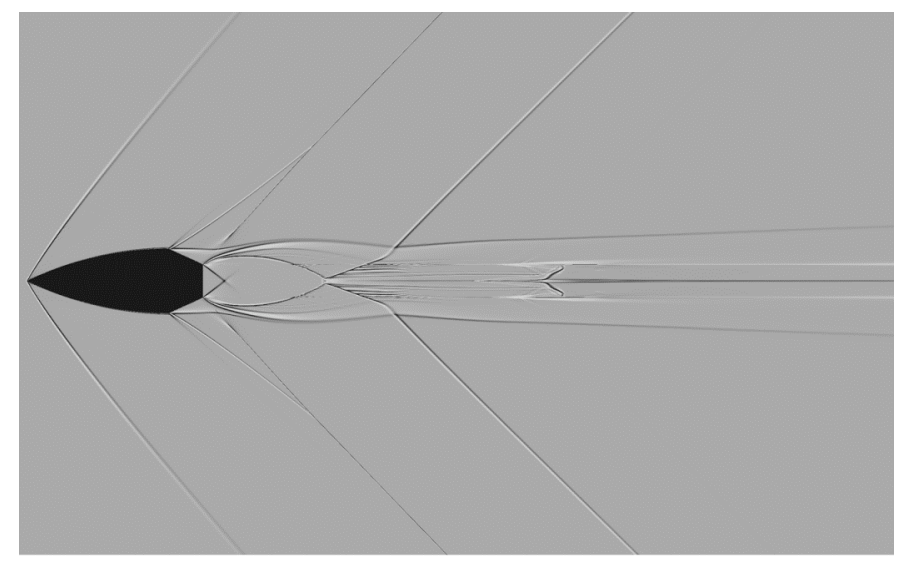

c) One-dimensional nozzle exit.

Figure 16. Concluded.

Figure 17 shows a comparison of the pressure distributions. The 1D plumes result in somewhat higher boat tail static wall pressures than the axisymmetric plume (Fig. 17a). Furthermore, the first shock in the centerline of the full-axisymmetric jet plume is upstream of the corresponding 1D shocks (Fig. 17b). There are significant differences in the sonic boom pressure signature as well (Fig. 17c). The 1D sonic boom tail shocks occur upstream of the fullaxisymmetric tail shock and are shifted upwards. This occurrence is a direct consequence of the wider 1D jet plumes as discussed previously. Finally, both of the 1D solutions miss the third shock in the tail shock train that was captured by the full-axisymmetric solution.

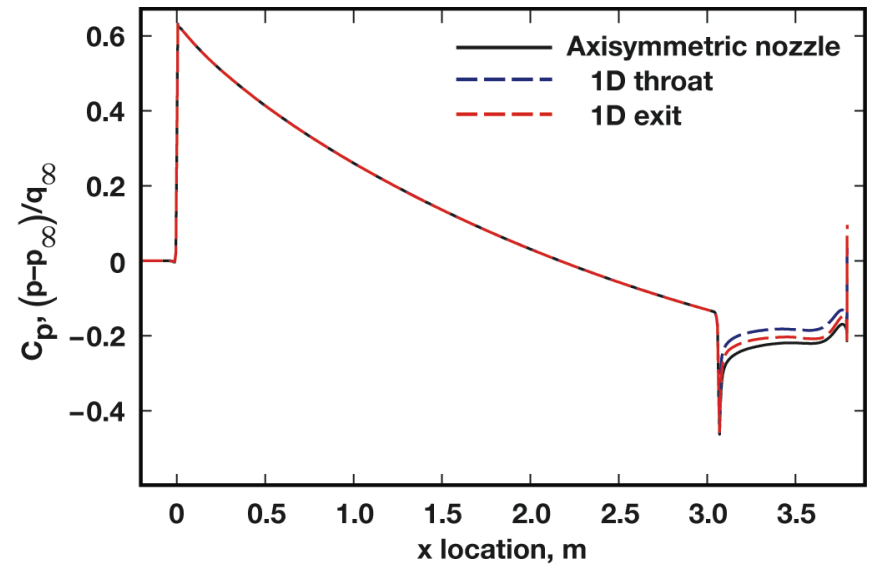

a) Bullet body wall static pressure.

Figure 17. One-dimensional nozzle flow effects; nozzle pressure ratio of 25.2. 


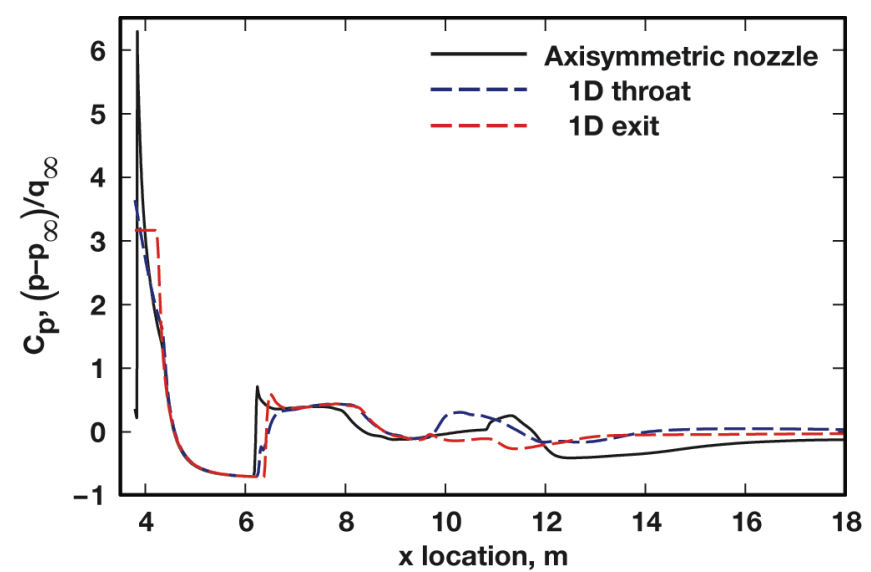

b) Jet plume centerline static pressure.

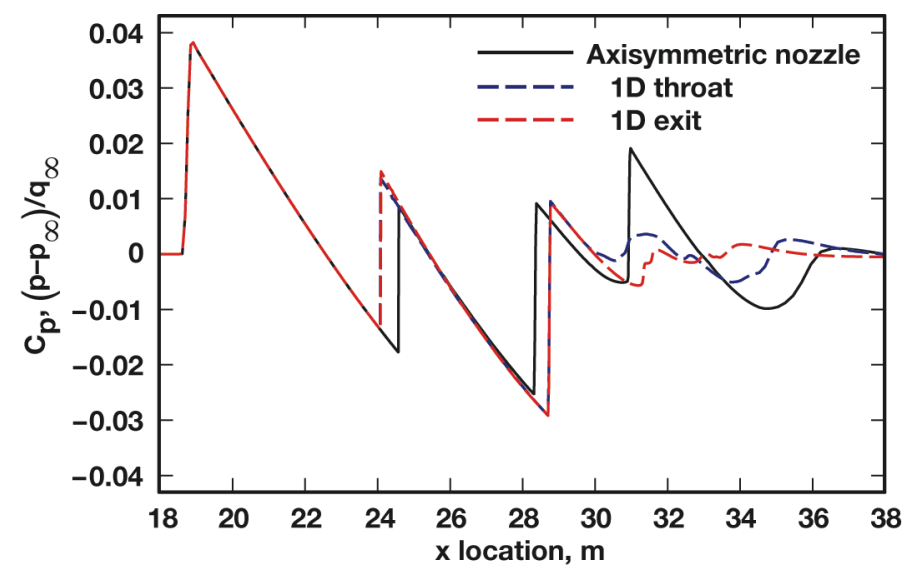

c) Sonic boom pressure signature $21.34 \mathrm{~m}$ from jet centerline.

Figure 17. Concluded.

\section{F. Nozzle Boat Tail Effects}

A boat tail was used in all of the axisymmetric CFD nozzle simulations conducted so far in the current study. As shown in Fig. 1, however, the actual nozzles on the NF-15B research aircraft do not have any boat tails that are faired in. The straight flaps of the aircraft research nozzles are exposed directly to freestream with only mechanical links connecting the flaps to supporting braces in the aft fuselage area of the aircraft. The mechanical links form a semiopen boat tail surface around the outside of the nozzle that the current axisymmetric approximation cannot model. To assess the effects that the nozzle boat tails could have on the plume flow field and the sonic boom signature, an axisymmetric CFD simulation was conducted without the boat tail at the nominal flight NPR value of 9.7. Results from simulations with and without the boat tail were then used to bound the effects that a nozzle boat tail might have on the aircraft sonic boom pressure signature.

Figure 18 shows the CFD-simulated shadowgrams. The flows are quantitatively similar except that without the boat tail, flow separation occurs over a much larger area in the aft region of the bullet body. The separated flow bubble actually forms a fluidic boat tail that smoothly connects the jet plume to the aft body of the model. Figure 19 shows a plot of the pressure results. With no boat tail, the static wall pressure remains more or less constant in the aft bullet area $(x>3 \mathrm{~m})$ because of the large flow separation bubble, as seen in Fig. 18b. The first plume shock also occurs farther downstream than in the case with the boat tail (Fig. 19b), resulting in a stronger first shock in the shock train downstream of the tail shock (Fig. 19c). Somewhat surprisingly, the lack of a boat tail does not significantly affect the strength and location of the tail shock in the sonic boom pressure signature. The "virtual" boat tail formed by the large separation bubble aft of the bullet body helps fair over the aerodynamic shape of the body even when no physical boat tail exists, resulting in very little difference in the far field sonic boom pressure signature. 


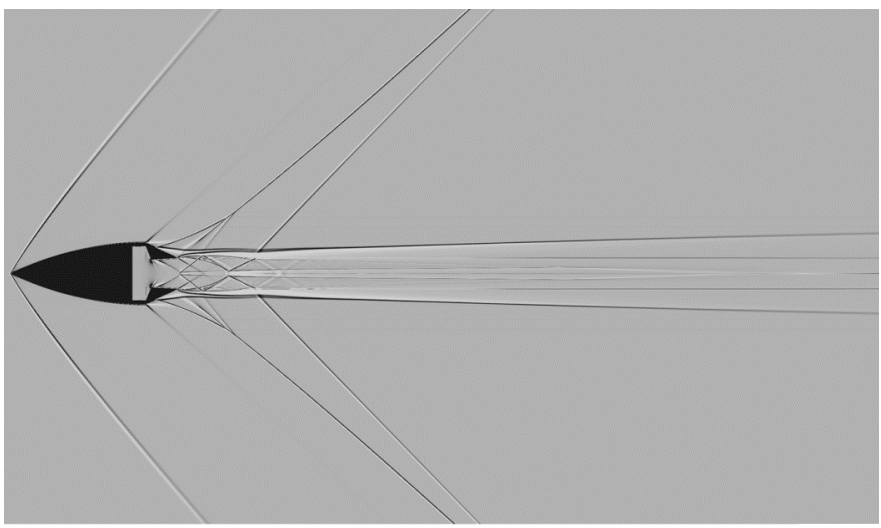

a) With boat tail.

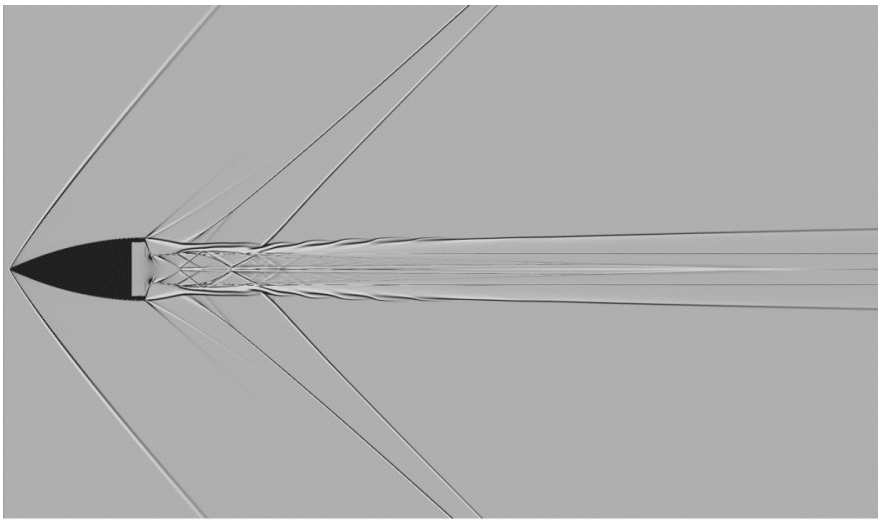

b) No boat tail.

Figure 18. Simulated shadowgraph visualizations; nozzle boat tail effects; nozzle pressure ratio of 9.7.

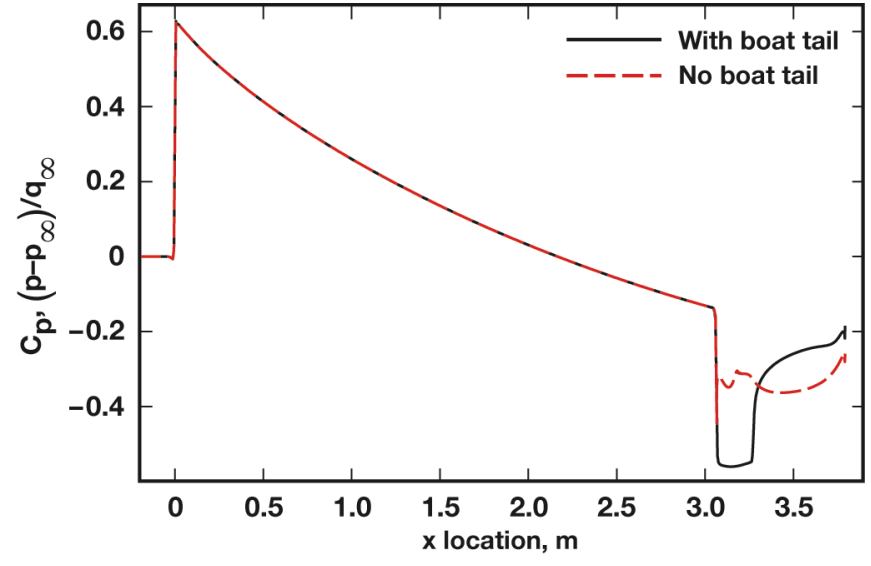

a) Bullet body wall static pressure.

Figure 19. Nozzle boat tail effects; nozzle pressure ratio of 9.7. 


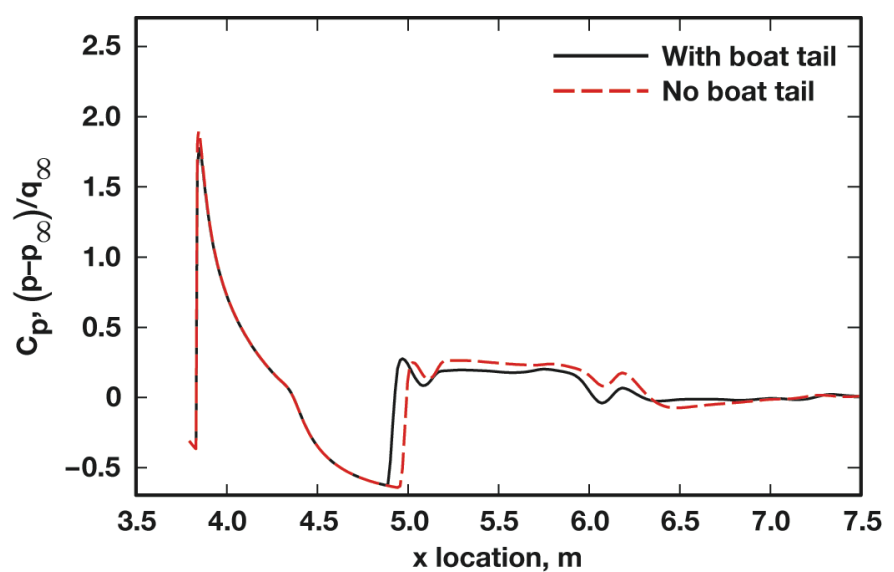

b) Jet plume centerline static pressure.

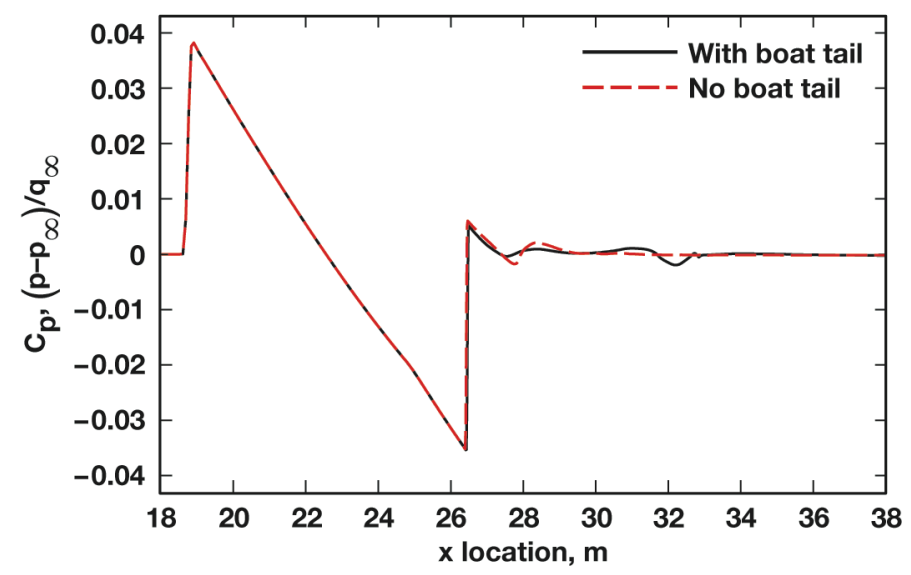

c) Sonic boom pressure signature $21.34 \mathrm{~m}$ from jet centerline.

Figure 19. Concluded.

\section{G. Nozzle Plenum Area Effects}

If the 1D nozzle flow approximation is used in an analysis, then the nozzle plenum area should have no effect on the flow at the nozzle exit plane, provided the flow is choked and supersonic in the divergent section of the nozzle. For multidimensional and axisymmetric nozzle flows, however, changes in the nozzle plenum area affect the nozzle exit flow because of changes in the geometry of the convergent section of the nozzle. To assess the effects that the nozzle plenum area variation could have on the plume flow field and the sonic boom signature, an axisymmetric CFD simulation was conducted with a nozzle plenum area that was approximately half of the nominal plenum area used in the standard nozzle test case, at the nominal flight NPR value of 9.7.

Figure 20 shows a plot of the pressure results. The convergent and divergent flap lengths, area ratios, and exit areas of the nozzle were kept fixed in both cases. As such, the nozzle with the smaller plenum area is longer than the nominal nozzle. As shown in Fig. 20a, the exit plane of the nominal nozzle is at an $x$ location of $3.79 \mathrm{~m}$, whereas the exit plane of the nozzle with the smaller plenum area is at an $x$ location of $3.97 \mathrm{~m}$. The static wall pressure is higher in the boat tail region for the nozzle with the smaller plenum area. The first plume shock is also stronger and sharper than that of the nominal nozzle, as seen in Fig. 20b. In general, however, Fig. 20c shows that a decrease in the nozzle plenum area does not significantly change the far field sonic boom signature. 


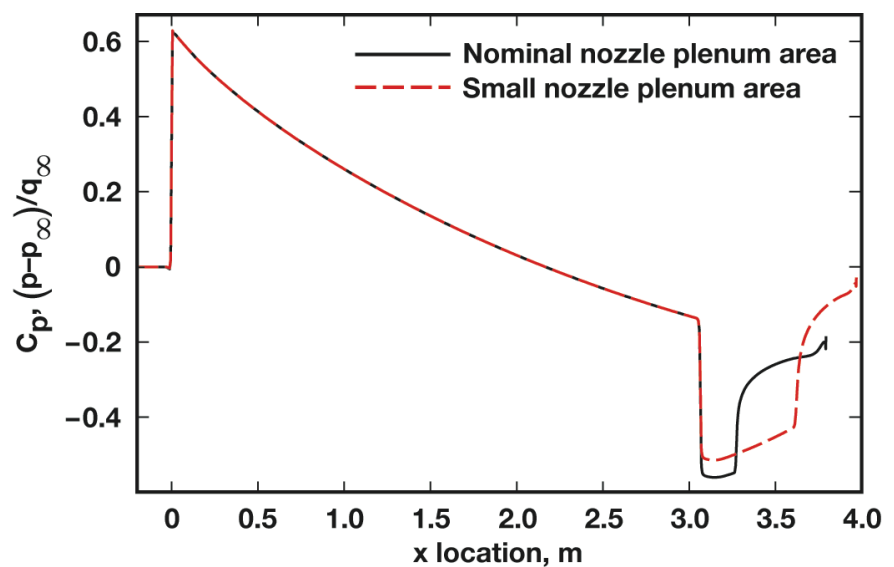

a) Bullet body wall static pressure.

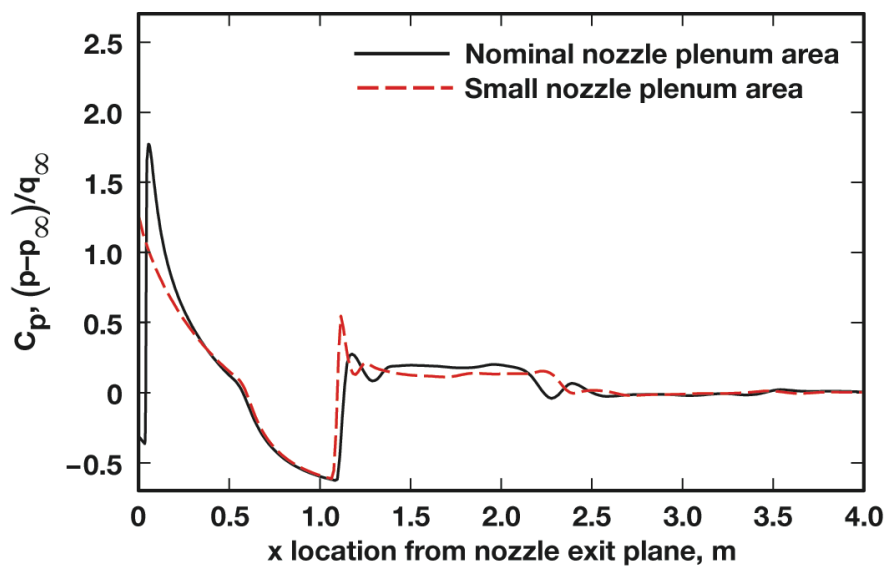

b) Jet plume centerline static pressure.

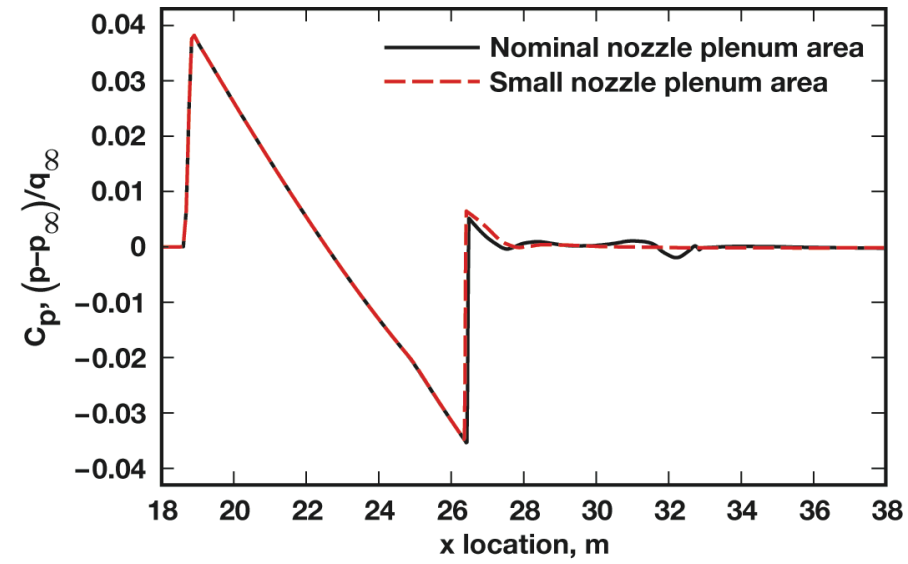

c) Sonic boom pressure signature $21.34 \mathrm{~m}$ from jet centerline.

Figure 20. Nozzle plenum area effects; nozzle pressure ratio of 9.7.

\section{Conclusion}

A computational fluid dynamics (CFD) analysis was conducted to study the nozzle exhaust plume effects on the sonic boom signature of a supersonic aircraft. A simplified axisymmetric nozzle geometry, representative of the 
nozzle on the NASA Dryden NF-15B, tail No. 837, Lift and Nozzle Change Effects on Tail Shock (LaNCETS) research aircraft, was considered.

Results showed that grid size, grid direction, and spatial order of accuracy of the CFD method are important for successful sonic boom signature prediction. The structured grid approach with grid lines parallel to the Mach wave direction was found to give the best results. Second-order accurate upwind methods are required for accurate sonic boom simulations. Furthermore, the Euler approach exaggerated the peaks and dips of the sonic boom signature, and full Navier-Stokes simulations provided better agreement with the experimental data.

The highly underexpanded nozzle flow provided more reduction in the tail shock strength in the sonic boom pressure signature than the overexpanded, perfectly expanded, and mildly overexpanded nozzle flows. The far field shock train was present only in the highly underexpanded jet plume solution and absent for all other cases. Fullaxisymmetric CFD simulations showed the flow physics inside the F-15 nozzle to be complex and multidimensional. Although the one-dimensional nozzle plumes looked quantitatively similar to the fullaxisymmetric plume, important flow features were either missing or incorrectly captured in the one-dimensional nozzle solutions. Finally, the lack of a nozzle boat tail and the variation in the nozzle plenum area produced very little differences in the strength and location of the far field sonic boom tail shock.

In this study, significant reduction in the tail shock strength was found as a result of operating the nozzle in a highly underexpanded condition. Therefore, the original LaNCETS flight research project objective, which studied the effects of changing the jet engine nozzle area ratio on the tail shock of a supersonic airplane, is sound. Even larger reductions in the aircraft tail shock strength could potentially be obtained by blending the aft-fuselage shaping with the nozzle boat tail shaping and applying an appropriate degree of underexpansion of the nozzle exhaust flow. In addition, nozzle thrust vectoring can change the lift distribution and nozzle exhaust plume of the aircraft and thus affect the sonic boom signature. Additional research is recommended with respect to wind-tunnel testing, flighttesting, and full-aircraft CFD studies in these promising areas.

\section{References}

${ }^{1}$ Seebass, R., George, A.R., "Sonic Boom Minimization," Journal of the Acoustical Society of America, Vol. 51, No. 2, part 3, Feb. 1972, pp. 686-694.

${ }^{2}$ Haering, E.A., Jr., Murray, J.E., Purifoy, D. D., Graham, D.H., Meredith, K.B., Ashburn, C.E., and Stucky, Lt. Col. M., "Airborne Shaped Sonic Boom Demonstration Pressure Measurements with Computational Fluid Dynamics Comparisons," AIAA-2005-9, Jan. 2005.

${ }^{3}$ Freund, D., Simmons, F., Howe, D., Cowart, R., and Grindle, T., "Lessons Learned: Quiet Spike ${ }^{\mathrm{TM}}$ Flight Test Program," AIAA-2008-130, Jan. 2008.

${ }^{4}$ Englert, G.W., "Operational Method of Determining Initial Contour of and Pressure Field About a Supersonic Jet," NASA TN D-279, 1960.

${ }^{5}$ Putnam, L.E., and Capone, F.J., "Experimental Determination of Equivalent Solid Bodies to Represent Jets Exhausting Into a Mach 2.20 External Stream," NASA TN D-5553, 1969.

${ }^{6}$ Barger, R.L., and Melson, N.D., "Comparison of Jet Plume Shape Predictions and Plume Influence on Sonic Boom Signature," NASA TP 3172, 1992.

${ }^{7}$ Nash, K.L., Whitaker, K.W., and Freeman, L. M., "Predicting Exhaust Plume Boundaries with Supersonic External Flows," Journal of Spacecraft and Rockets, Vol. 31, No. 5, Sept.-Oct. 1994, pp. 773-777.

${ }^{8}$ Castner, R.S., "Analysis of Plume Effects on Sonic Boom Signature for Isolated Nozzle Configurations," AIAA-2008-3729, June 2008.

${ }^{9}$ White, J.A., and Morrison, J.H., "A Pseudo-Temporal Multi-Grid Relaxation Scheme for Solving the Parabolized NavierStokes Equations," AIAA-1999-3360, June 1999.

${ }^{10}$ Carlson, H.W., Mack, R.J., and Morris, O.A., “A Wind-Tunnel Investigation of the Effect of Body Shape on Sonic-Boom Pressure Distributions," NASA TN D-3106, 1965.

${ }^{11}$ Shrout, B.L., Mack, R.J., and Dollyhigh, S.M., "A Wind-Tunnel Investigation of Sonic-Boom Pressure Distributions of Bodies of Revolution at Mach 2.96, 3.83, and 4.63,” NASA TN D-6195, 1971.

${ }^{12}$ Edwards, J.R., "A Low-Diffusion Flux-Splitting Scheme for Navier-Stokes Calculations," Journal of Computers \& Fluids, Vol. 26, No. 6, July 1997, pp. 635-659.

${ }^{13}$ Carlson, H.W., "Correlation of Sonic-Boom Theory with Wind-Tunnel and Flight Measurements,” NASA TR R-213, 1964.

${ }^{14}$ Menter, F.R., "Two-Equation Eddy-Viscosity Turbulence Models for Engineering Applications," AIAA Journal, Vol. 32, No. 8, Aug. 1994, pp. 1598-1605.

${ }^{15}$ Van Dyke, M., Editor, An Album of Fluid Motion, 10th ed., The Parabolic Press, Stanford, California, 1982. 